\title{
GENETIC AND MOLECULAR CHARACTERIZATION OF A DISTILLER'S YEAST
}

\author{
by \\ ANNE KRISTINE KEIDING \\ The Danish Distilleries Ltd. Raffinaderivej 10, DK-2300 Copenhagen S, \\ Department of Physiology, Carlsberg Laboratory, Gamle Carlsberg Vej 10, DK-2500 Copenhagen Valby \\ and \\ Institute of Genetics, University of Copenhagen \\ Øster Farimagsgade 2A, DK-1353 Copenhagen K
}

Keywords: Saccharomyces cerevisiae, sporulation, mating types, mutagenesis, tetrad analysis, DNA hybridization, $H I S 4, L E U 2, M A T$, silent mating type loci, $H O$, ploidy

Auxotrophic mutants have been induced by UV-irradiation and EMS treatment in meiotic segregants of a distiller's production strain of yeast. In complementation tests some of the mutants were allelic to adel, ade3, lys 2 , met 13, trpI, ural and ura 4 of standard strains of S. cerevisiae.

Crosses were made between two spore-derived clones of the distiller's strain and haploid S. cerevisiae strains carrying several auxotrophic markers. Tetrad analysis of the mating products revealed that the spore-derived clones were disomic for six and seven chromosomes, respectively.

Chromosomes III from the distiller's production strain were compared to their counterparts in standard strains of S. cerevisiae at several loci. Cloned DNA from HIS4, LEU2 and MAT loci from the standard strain were used as hybridization probes to test the nucleotide sequence homology at these loci and the silent mating type genes $H M L$ and $H M R$. Restriction site polymorphisms were not detected inside the loci but in regions adjacent to them. These could be exploited in combination with tetrad analysis to identify four different chromosomes III in the distiller's strain. Of the four chromosomes, three were lacking $H M L$ and one was lacking $H M R$. The data are consistent with the assumption that all loci tested are organized in the same order as in the genetically analysed standard strains.

\section{INTRODUCTION}

From a genetic point of view, industrial yeasts are as yet poorly characterized which is in contrast to the strains of S. cerevisiae on which our knowledge of yeast genetics is based. Although some of the industrial yeasts sporulate reasonably well $(14,16)$, the spore viability is often poor and ability of the spore-derived clones to mate is frequently lacking. Several factors are thought to cause the poor spore viability. Among them can be aneuploidy or polyploidy, which have been observed in several industrial strains $(10,14,16)$. Reduced recombination at meiosis leading to non-disjunction of chromosomes has been identified as a cause for low spore viability in brewers yeast (33). Hetero-

Abbreviations: $\mathrm{bp}=$ base pair; $\mathrm{EMS}=$ ethyl methanesulphonate; $\mathrm{EtBr}=$ ethidium bromide; $\mathrm{kb}=\mathrm{kilobase}$ pair; $\mathrm{NF}$ $=$ non-fermentable medium; $\mathrm{NPD}=$ non parental type; $\mathrm{PD}=$ parental ditype; $\mathrm{SC}=$ synthetic complete; $\mathrm{SD}=$ Synthetic dextrose; TT = tetratype; UV = ultra violet; YPD = yeast extract peptone dextrose; YPG = yeast extract peptone glycerol. 
Table I.

Standard S. cerevisiae strains used in this study

\begin{tabular}{|c|c|c|}
\hline Strain & Genotype & Source \\
\hline S288C & MATa mal gal2 & Cold Spring Harbor Lab. \\
\hline D273-11A & MATa adel hisl & Cold Spring Harbor Lab. \\
\hline D286-2A & MATa adel hisI & Cold Spring Harbor Lab. \\
\hline D517-4B & MATa ade2 lys 9 & Cold Spring Harbor Lab. \\
\hline D609-28C & MATa arg4-17 his5-2 lysI-1 trpl-1 tyr7-1 & Cold Spring Harbor Lab. \\
\hline A9275C & MATa his4-29 HOLI-1 $\mathrm{can}^{\mathrm{s}}$ & G. FINK \\
\hline $\mathrm{X} 422$ & $\begin{array}{l}\text { MATa adel trp1 gall cdc14 his2 SUP6 tyr7 } \\
\text { cly3 met } 10\end{array}$ & H. ROMAN \\
\hline $\mathrm{X} 426$ & MAT $\alpha$ ade5 lys5 aro2 cyh2 trp5 leul met13 & H. ROMAN \\
\hline 168 & MAT a ade1 gall lys 2 tyrl his 7 ural ade 2 & G. STEWART \\
\hline 194 & $M A T \mathbf{a}$ adel trp5 MAL6 & G. STEWART \\
\hline 207 & $\begin{array}{l}\text { MATa ade1 ura3 his2 gal trp5 leul lys7 } \\
\text { met } 2 \text { MAL3 }\end{array}$ & G. STEWART \\
\hline 210 & MATa adel gall trpl ura3 his2 leul met 14 & G. STEWART \\
\hline $483 / 1 d$ & MAT a ade2-1 canl-100 his5-2 lys1-1 supQ5 & B. $\operatorname{Cox}$ \\
\hline XXI-I-49 & MATa his4-594 ade2-40 trp5b cyh2 lys1 & T. NiLSSON-TILlGREN \\
\hline all & MATa trpl ura4 his4-29 arg4-16 & T. NILSSON-TILLGREN \\
\hline N248-1A & MATa adel gall leul his2 ura3 trpl met 14 & G. KAWASAKI \\
\hline $\mathrm{N} 248-1 \mathrm{C}$ & MATa adel gall leul his2 ura3 trpl met14 & G. KAWASAKI \\
\hline N435-2A & MATa his7 lys7 met6 arg1 gal4 MAL2 SUC & G. KAWASAKI \\
\hline N442-4A & $\begin{array}{l}\text { MATa his6 ade2 lys9 ural trp5 met2 arg } 4 \\
\text { mal suc }\end{array}$ & G. KAWASAKI \\
\hline $\mathrm{N} 442-5 \mathrm{C}$ & $\begin{array}{l}\text { MATa his6 ade2 lys9 ural trp5 met } 2 \text { arg } 4 \\
\text { mal suc }\end{array}$ & G. KaWASAKI \\
\hline N435-1A & MATa his7 lys 7 met6 arg1 gal4 MAL2 SUC & G. KAWASAKI \\
\hline 3654-1D & MATa his4 trp1 ura4 ade6 leu2 lys2 thr4 & D. HAWTHORNE \\
\hline $3654-5 \mathrm{~A}$ & $\begin{array}{l}\text { MATa his4 trpl ura4 ade6 leu2 lys } 2 \text { thr4 } \\
\text { tyrl arg4 MAL2 gall }\end{array}$ & D. HAWTHORNE \\
\hline $3971-5 B$ & $\begin{array}{l}\text { MAT a ilv1 met8 trpl ura } 3 \text { gallo ura } 4 \text { leu2 } \\
\text { lys } 1 \text { canl ade5, } 7 \text { arolD }\end{array}$ & R.K. MORTIMER \\
\hline K398-4D & $\begin{array}{l}\text { MATa spoll ura3 ade6 arg } 4 \text { aro } 7 \text { asp } 5 \\
\text { met } 14 \text { lys } 2 \text { trpl pet } 17\end{array}$ & S. KLAPHOLZ \& R.E. EsPOSITO (29) \\
\hline K399-7D & MATa spoll ura3 his2 leul lysI met4 pet 8 & S. KLAPHOLZ \& R.E. ESPOSITO (29) \\
\hline K396-11A & $\begin{array}{l}\text { MATa spoll ura3 adel hisl leu } 2 \\
\text { lys } 7 \text { met } 3 \text { trp } 5\end{array}$ & S. KLAPHOLZ \& R.E. ESPOSITO (29) \\
\hline K396-22B & $\begin{array}{l}\text { MATa spoIl ura3 adel hisl leu2 lys } 7 \text { met3 } \\
\text { trp5 }\end{array}$ & S. KLAPHOLZ \& R.E. EsPOSITO (29) \\
\hline $37.72-29 \mathrm{~A}$ & MATa ade6 trp5 met13 lys 5 ural & F. ZIMMERMANN \\
\hline $37.72-30 \mathrm{C}$ & MATa ade6 trp 5 met 13 lys 5 & F. ZIMMERMANN \\
\hline $37.72-23 \mathrm{C}$ & MATa ades leul cyh2 aro 2 ades ural & F. ZIMMERMANN \\
\hline $37.72-4 \mathrm{~A}$ & MATa ade3 leul cyh2 aro 2 ade 5 & F. ZIMMERMANN \\
\hline D8-25A & $\begin{array}{l}\text { MATa ade5 lys5 aro } 2 \text { metl } 3 \text { cyh2 trp5 leul } \\
\text { ade } 2-40\end{array}$ & F. ZIMMERMANN \\
\hline
\end{tabular}

zygosity for recessive lethal mutations and their segregation in the spores is to be considered as another reason for spore lethality. Reduced spore viability coupled with a majority of non- maters among the germinating spores makes traditional genetic analyses difficult.

A distiller's strain of $S$. cerevisiae has been sporulated and the spores dissected (7). $42 \%$ of 
the spores germinated and of the colonies derived $61 \%$ were able to sporulate. Of the remaining colonies nearly all expressed mating type with a preponderance of a maters. This paper describes genetic and molecular characterizations of spore-derived clones of this distiller's yeast, including attempts to establish the ploidy level of the strain. Rare mating of the strain to genetically defined strains indicates an excess of $M A T$ a over MATa mating type genes. Auxotrophic mutants are isolated from meiotic segregants. By testing mating and sporulation ability of meiotic segregants mitotic instability due to loss of chromosome III is revealed. Tetrad analyses of crosses between meiotic segregants and genetic standard strains of S. cerevisiae uncover disomy for several chromosomes. Finally, analysis of chromosome III by hybridization of cloned sequences from HIS4, LEU2 and $M A T \alpha$ to endonuclease restricted DNA shows that this distiller's yeast contains four copies of chromosome III. A close homology between these chromosomes and chromosome III of the standard strains of S. cerevisiae is demonstrated.

\section{MATERIALS AND METHODS}

\subsection{Strains, recombinant molecules, media and enzymes}

The production strain DDSF 102 from the Danish Distillers Ltd. culture collection, S. cerevisiae strain $A$, was analysed in this study with 284 different meiotic segregants, referred to as $A_{1}$ to $A_{402}$ (some numbers have not been used) and with the standard genetic strains listed in Table I.

For molecular hybridizations the plasmids pC503 containing HIS4 (22), pYF91.2 with LEU2 (45), and M271 with MATa, (21) were used.

The following media were employed: YPD contained $1 \%$ Difco yeast extract, 2\% Difco peptone, $2 \%$ glucose. Some strains grew very slowly in this medium but better when the glucose concentration was raised to $4 \%$. YPG contained $1 \%$ yeast extract, $2 \%$ peptone, $3 \%$ glycerol. Synthetic minimal medium (SD) and synthetic complete medium (SC) were prepared according to ZIMMERMANN (48). Pre-sporulation medium (PS) contained $0.8 \%$ yeast extract,
$0.3 \%$ peptone, $10 \%$ glucose, $\mathrm{pH} 6.5$. Sporulation medium contained $1 \%$ potassium acetate, $0.1 \%$ yeast extract, $0.05 \%$ glucose. Non-fermentable medium (NF) contained $0.67 \%$ Difco Yeast Nitrogen Base without amino acids, $1 \%$ succinic acid, $0.6 \% \mathrm{NaOH}, 1 \%$ glycerol, $1 \%$ glutamate, $1 \%$ aspartate, $1 \%$ lactate, $1 \%$ ethanol. Ethidium bromide $(\mathrm{EtBr})$ was used at a concentration of $25 \mu \mathrm{g} \times \mathrm{ml}^{-1}$. Plates were solidified with $2 \%$ Bacto agar.

Restriction endonucleases and DNA polymerase I were purchased from Boehringer Mannheim Biochemicals.

\subsection{Mutagenesis and isolation of mutants}

UV mutagenesis was carried out as follows: Cells were grown in liquid YPD to mid-log phase and washed twice in sterile water. For UV-irradiation cells were agitated in a $5 \mathrm{ml} 0.1 \mathrm{M}$-potassium-phosphate-buffer suspension in a petri dish at a concentration of $10^{7}$ cells $\times \mathrm{ml}^{-1}$ and treated with a dose rate of $9.22 \mathrm{~J} \times \mathrm{s}^{-1} \times \mathrm{m}^{-2}$. The UV-irradiation time was $3 \mathrm{sec}$ and $40 \mathrm{sec}$, which gave doses of $27.7 \mathrm{~J} \times \mathrm{m}^{-2}$ and $369 \mathrm{~J} \times \mathrm{m}^{-2}$, respectively. Dilutions, plating as well as subsequent growth were carried out in the dark to eliminate the action of photorepair (19).

Ethyl methanesulphonate (EMS) mutagenesis was performed as follows: The cultures were grown to early stationary phase, the cells washed twice in sterile water and suspended in buffer. EMS was added and incubation was performed by shaking for 2 hours at $30^{\circ} \mathrm{C}$. The cells were washed twice in $5 \mathrm{ml} 5 \%$ sodium thiosulfate and once in water. The EMS concentrations were $1 \%$ and $4 \%$, respectively.

All mutagenized cultures were suspended in YPD and shaken for 24 hours at $30^{\circ} \mathrm{C}$.

Enrichment for auxotrophic mutants was performed by heat killing of exponentially growing cells essentially as described by WALTON et al. (47). A stationary phase culture in YPD was washed and diluted tenfold in SD or SD + adenine + histidine. After 4 hours of shaking, 5 $\mathrm{ml}$ of the culture was heat treated which kills growing cells while permitting most stationary phase cells to survive. The best conditions for the strains used were $52{ }^{\circ} \mathrm{C}$ for four minutes. The treated cells were grown for 24 hours in YPD, 
followed by plating on YPD. Auxotrophic mutants were found by replica plating onto SD. Colonies which grew on YPD, but failed to grow on $\mathrm{SD}$, were isolated and the growth requirements were determined on SC lacking individual nutrients.

\subsection{Characterization of mutants}

Complementation analysis was carried out by crossing the auxotrophic mutants with the genetically marked strains of S. cerevisiae listed in Table I. A mutation was determined to be allelic to a specific gene in a tester strain when complementation on SD medium failed.

\subsection{Mating type tests}

\subsubsection{Induction of respiratory deficient mutations}

Strains to be tested were made respiratory deficient, tho- by streaking on EtBr-containing medium (43).

\subsubsection{Determination of mating type}

Single rho ${ }^{-}$colonies derived from the industrial strains were mixed with a or $\alpha$ tester strains on YPD plates. After 2 or 5 days at $30^{\circ} \mathrm{C}$, the cell mass was replica plated onto NF plates and the ability to grow was tested after $3-5$ days at $30^{\circ} \mathrm{C}$.

\subsubsection{Rare mating on solid medium}

Lawns of rho cells $\left(5 \times 10^{6}-5 \times 10^{7}\right.$ cells $\times$ plate $^{-1}$ ) were replica plated onto YPD plates together with a tester strain of the same density. After 2 days of growth, replica plating was carried out onto NF plates and growth was tested after 5 days at $30^{\circ} \mathrm{C}$.

\subsubsection{Rare mating in liquid medium}

$\mathrm{Rho}^{-}$cells and tester strains were grown in liquid YPD to $\log$ phase. All cultures were concentrated to $10^{7}$ cells $\times \mathrm{ml}^{-1}$ by centrifugation, and equal amount of rho ${ }^{-}$cells and tester strain cells were mixed. Incubation was performed by shaking at $30^{\circ} \mathrm{C}$ for 1 hour, whereafter the suspension was diluted tenfold and growth allowed to continue for an additional 18 hours. A sample from each mixture was plated on YPG, SD and NF plates. Growth was tested after $2-5$ days at $30^{\circ} \mathrm{C}$.

\subsection{Test sporulation}

After 2 days at $30^{\circ} \mathrm{C}$ on a PS plate, yeast cells were transfered to sporulation plates and incubated at $10^{\circ} \mathrm{C}, 20^{\circ} \mathrm{C}, 30^{\circ} \mathrm{C}$ and $37^{\circ} \mathrm{C}$ for different lengths of time. Sporulation was detected according to the malachite green - safranin staining procedure described by SCHAEFFER and FULTON (40).

\subsection{Tetrad analysis}

Crosses were made between meiotic segregants of the industrial and genetically marked strains. After sporulation, the microdissection and tetrad analyses were carried out as described by HAWTHORNE and MORTIMER (18).

\subsection{DNA purification}

Supercoiled plasmid DNA from E. coli was isolated by the alkaline-sodium dodecyl sulfate (SDS) procedure (3) 50 times scaled up (21) and purified by centrifugation in $\mathrm{CsCl} / \mathrm{EtBr}$ gradients. Total DNA from yeast was isolated from 11 cultures by the method of CAMERON et al. (5). No diethyl pyrocarbonate treatment was performed and the DNA was purified by centrifugation in $\mathrm{CsCl} / \mathrm{EtBr}$ gradients.

\subsection{Electrophoresis and purification of spe- cific DNA fragments}

Gel electrophoresis of DNA (27) was performed in $0.7 \%$ agarose or $2 \%$ low melting agarose. Restriction fragments were purified from low melting point agarose gels by extraction with phenol (30). After centrifugation the DNA was made $0.3 \mathrm{M}$ in sodium acetate and precipitated with 2.5 volumes of $96 \%$ ethanol.

\subsection{In vitro labelling of DNA, Southern trans- fers and hybridization \\ Plamids or purified restriction fragments were}


labelled in vitro with ${ }^{\text {sh }} \mathrm{P}$-dATP (Radiochemical Centre Amersham) by nick translation according to RIGBY et al. (36). After gel electrophoresis, restriction endonuclease fragments of genomic yeast DNA were transferred to nitrocellulose filters (Millipore, HAWP 000 10) by the procedure of SOUTHERN (44) modified according to HoLMBERG et al. (22). Hybridization of labelled DNA to DNA immobilized on nitrocellulose filters was performed as described by DENHARDT (8) with the modification of JEFFREYS and FlAVELL (25). Autoradiographic exposure was for $1-14$ days with Kodak X-Omatic regular intensifying screens at $-80^{\circ} \mathrm{C}$.

\section{RESULTS}

\subsection{UV dose response}

In order to compare the behaviour of $A_{91}$, a meiotic product of strain $A$, with the behaviour of two haploid genetically characterized strains, UV-survival curves of each strain were determined. The results are shown in Figure 1. It can be seen that $A_{91}$ is more sensitive to UV light than the haploid strains in the low dose range whereas it is less sensitive in the high dose range. This behaviour is very similar to that reported by PARRY and CoX for a strain containing $18 \%$ less DNA than a normal diploid (34).

\subsection{Mutagenesis}

\section{2.l. Mutagen doses}

Mutagenesis was carried out on strains $\mathrm{A}_{91}$ and $A_{209}$ as described in section 2.2, either with UV-irradiation or with EMS treatment. Both strains were prototrophs and of mating type $\alpha$ and $\mathbf{a}$, respectively. Two different doses of mutagen were used. The low dose was chosen to obtain single point mutations without extensive genetic damage which could affect the growth rate and/or the industrial qualities. As the two strains probably are diploid, a high dose was also chosen for induction of mitotic recombination and chromosome loss.

\subsubsection{Characterization of mutants}

Five catagories of mutants were obtained. Mutants in nitrogen metabolism and colony

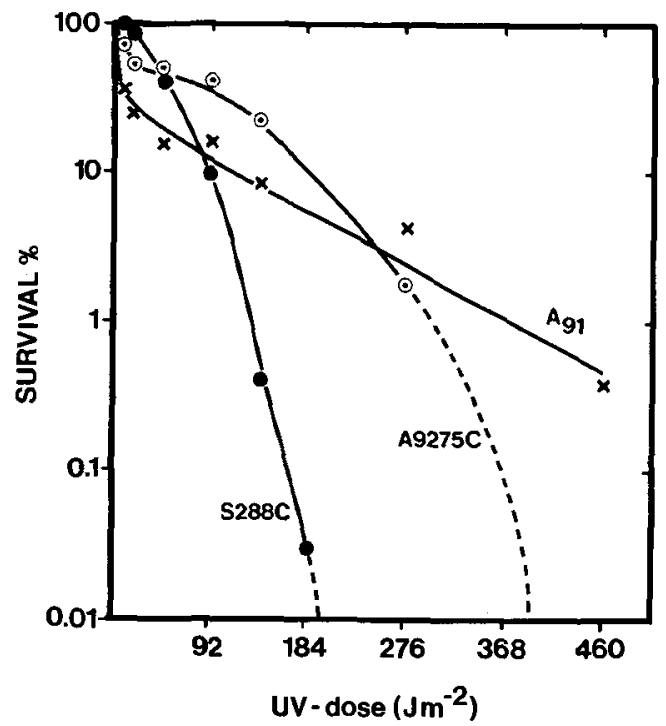

Figure 1. Survival curves of a meiotic segregant of distiller's yeast $\left(\mathrm{A}_{9_{1}}\right)$ and two haploid strains $(\mathrm{S} 288 \mathrm{C}$, A9275C) after UV treatment according to section 2.2. The dashed lines are extrapolations as no survivors of $\mathrm{S} 288 \mathrm{C}$ were detected at $276 \mathrm{~J} \times \mathrm{m}^{-2}$ and no survivors of $\mathrm{A} 9275 \mathrm{C}$ at $460 \mathrm{~J} \times \mathrm{m}^{-2}$.

morphology as well as respiratory deficient and leaky auxotrophic mutants were not further characterized.

The fifth catagory comprising auxotrophic mutants is listed in Table II. All the mutants have been crossed with genetically marked strains of S. cerevisiae, as described in section 2.3. Seven of the ten auxotrophic mutant types have been found to be allelic to known $\mathrm{S}$. cerevisiae genes, as shown in Table II. While mutants in ten different genes were isolated from strain $\mathrm{A}_{91}$, mutagenesis of $\mathrm{A}_{209}$ yielded only ade 3 mutants. Four of the mutant types could not be assigned to genes due to the lack of suitable tester strains. The mutants with the phenotype $\mathrm{Glu}^{-} /$ Lys $^{-}$rho $^{-}$may map in glu2, glu 3 or glu5. Ade could be either ade4, ade7, ade8 or ade9. Due to the large number of non-allelic methionine genes, there are also several possibilities for the Met mutants. Auxotrophic mutants were only obtained when mutagenesis was followed by thermal selection. However, even in this case no mutants were found in some experiments. 
Table II.

Mutants isolated from meiotic segregants of strain $A$

\begin{tabular}{|c|c|c|c|c|c|c|c|}
\hline $\begin{array}{l}\text { Experi- } \\
\text { ment } \\
\text { no. }\end{array}$ & $\begin{array}{l}\text { Strain } \\
\text { mutagenized }\end{array}$ & Mutagen & $\begin{array}{l}\text { Survival } \\
\%\end{array}$ & $\begin{array}{l}\text { Number of } \\
\text { colonies } \\
\text { tested }\end{array}$ & $\begin{array}{l}\text { Number of } \\
\text { mutants }\end{array}$ & $\begin{array}{l}\text { Phenotype or } \\
\text { genotype and } \\
\text { chromosome no. }\end{array}$ & $\begin{array}{l}\text { Mutant } \\
\text { no. }\end{array}$ \\
\hline 1 & $\mathrm{~A}_{91}$ & EMS & 0.5 & 450 & 18 & $M A T \alpha$ ural(XI) & KK6 \\
\hline 2 & $\mathbf{A}_{91}$ & UV & 15 & 550 & 2 & MATa adel (I) & KK1 \\
\hline 3 & $A_{91}$ & UV & 1.5 & 500 & 3 & $M A T a \operatorname{ura} 4(\mathrm{XII})$ & KK3 \\
\hline 4 & $\mathbf{A}_{91}$ & UV & 1.5 & 2000 & $\begin{array}{l}3 \\
1\end{array}$ & $\begin{array}{l}\text { MATa } \operatorname{trpl}(\mathrm{IV}) \\
\operatorname{ade} 3(\mathrm{VII})^{\mathrm{xx}}\end{array}$ & $\begin{array}{l}\text { KK7 } \\
\text { KK29 }\end{array}$ \\
\hline 5 & $A_{91}$ & UV & 15 & 2200 & $\begin{array}{r}2 \\
21\end{array}$ & $\begin{array}{l}M A T \alpha \text { Glu /Lys rho- } \\
M A T \alpha \text { ade3(VII) }\end{array}$ & $\begin{array}{l}\text { KK12 } \\
\text { KK23 }\end{array}$ \\
\hline 6 & $A_{91}$ & EMS & 65 & 2500 & $\begin{array}{l}3 \\
1 \\
3 \\
1\end{array}$ & 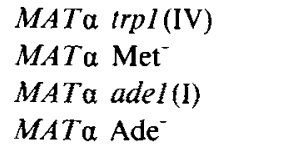 & $\begin{array}{l}\text { KK9 } \\
\text { KK11 } \\
\text { KK14 } \\
\text { KK34 }\end{array}$ \\
\hline 7 & $A_{91}$ & EMS & 0.5 & 1800 & $\begin{array}{r}2 \\
2 \\
16\end{array}$ & 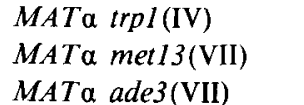 & $\begin{array}{l}\text { KK8 } \\
\text { KK10 } \\
\text { KK15 }\end{array}$ \\
\hline $\begin{array}{l}8 \\
9\end{array}$ & $\begin{array}{l}A_{99}{ }{ }^{x} \\
A_{0,1}{ }^{x}\end{array}$ & $\begin{array}{l}\text { UV } \\
\text { UV }\end{array}$ & $\begin{array}{l}15 \\
1.5\end{array}$ & $\begin{array}{l}1500 \\
1600\end{array}$ & $\begin{array}{l}0 \\
0\end{array}$ & & \\
\hline 10 & $\mathrm{~A}_{91}{ }^{{ }^{3}}$ & EMS & 65 & 1200 & $\begin{array}{l}1 \\
2\end{array}$ & $\begin{array}{l}M A T \alpha \text { adel(I) } \\
M A T \alpha \operatorname{ura} 4 \text { (XII) }\end{array}$ & $\begin{array}{l}\text { KK71 } \\
\text { KK70 }\end{array}$ \\
\hline 11 & $\mathrm{~A}_{91}{ }^{\mathrm{x}}$ & EMS & 0.5 & 1900 & $\begin{array}{l}1 \\
1\end{array}$ & $\begin{array}{l}\text { MATa lys2(II) } \\
M A T \alpha \text { Met }^{-}\end{array}$ & $\begin{array}{l}\text { KK68 } \\
\text { KK69 }\end{array}$ \\
\hline 12 & $\mathrm{~A}_{209}$ & UV & 15 & 1200 & 0 & & \\
\hline 13 & $\mathrm{~A}_{209}$ & UV & 1.5 & 1400 & 5 & MATa ade3(VII) & KK 19 \\
\hline 14 & $\mathbf{A}_{309}$ & EMS & 65 & 1100 & 3 & MATa ade3(VII) & KK20 \\
\hline 15 & $A_{209}$ & EMS & 0.5 & 1600 & 0 & & \\
\hline
\end{tabular}

$\times$ The thermoselection also included selection against ade 3 by growing the cells in $\mathrm{SD}+$ adenine + histidine prior to heat treatment.

${ }^{x *}$ KK29 had lost the mating type but was able to sporulate.

In experiment 1 (Table II), $4 \%$ of the tested colonies were ural mutants. Probably they all descended from the same mutagenized cell. This is also a possibility in other experiments in which more than one colony showed the same mutant phenotype. In experiments 5 and 7 an unexpected high number of ade 3 mutants relative to the other mutants was obtained. Thus it seems very easy to recover ade 3 mutants and a remarkably high number of independently arising ade 3 mutants were found. In four of the experiments the thermal selection was combined with selection against ade3 (26): The cells were grown in SD + adenine + histidine prior to the heat treatment in order to make the ade3 mutants heat sensitive. In experiment 10 which included selection against ade 3 it is seen that the thermal selection is not completely efficient: Despite the selection against Ade mutants a red colony appeared which turned out to be an adel mutant.

\subsection{Analysis of $M A T$ alleles by the rare mating technique}

The appearance of maters from a non-mating strain can be caused by mitotic recombination or by chromosome loss. Rare matings of frequencies higher than $10^{-6}$ have been shown to be due mainly to mitotic recombination (17), and the difference in frequency between the appearance of $a$ and $a$ maters reflects the number of 
Table III.

Rare mating of strain A with tester strains

\begin{tabular}{lllllr}
\hline $\begin{array}{l}\text { Experiment } \\
\text { no. }\end{array}$ & $\begin{array}{l}\text { Tester } \\
\text { strain }\end{array}$ & $\begin{array}{l}\text { Mating } \\
\text { type }\end{array}$ & $\begin{array}{l}\text { Number of } \\
\text { cells }\end{array}$ & $\begin{array}{l}\text { Mating } \\
\text { conditions }\end{array}$ & $\begin{array}{l}\text { Number of rare } \\
\text { mating products }\end{array}$ \\
\hline 1 & D273-11A & $a$ & $10^{7}$ & solid medium & 140 \\
& D286-2A & a & $10^{7}$ & $-“-$ & 54 \\
2 & D273-11A & $\alpha$ & $10^{8}$ & $-“-$ & 2500 \\
& D286-2A & a & $10^{8}$ & $-“-$ & 500 \\
3 & K396-22A & $\alpha$ & $2 \times 10^{7}$ & $-“-$ & 500 \\
4 & K396-11A & a & $2 \times 10^{7}$ & $-“-$ & 25 \\
& K396-22A & $\alpha$ & $2 \times 10^{7}$ & liquid medium & 5000 \\
5 & K396-11A & a & $2 \times 10^{7}$ & $-“-$ & 0 \\
& K396-22A & $\alpha$ & $2 \times 10^{7}$ & $-“-$ & $2.5 \times 10^{5}$ \\
& K396-11A & a & $2 \times 10^{7}$ & $-“-$ & 3 \\
\hline
\end{tabular}

$M A T \mathrm{a}$ and $M A T \alpha$ alleles in the individual cell (17).

In five independent experiments strain A was mated to tester strains according to the procedures described in sections 2.4.3 and 2.4.4. The results are listed in Table III. On solid medium the frequency of matings ranged from $1.25 \times 10^{-6}$ to $2.5 \times 10^{-5}$ and the ratio between cells of a mating type to cells of $a$ mating type ranged from 3 to 20 . In liquid medium the frequency of matings ranged from $2.5 \times 10^{-4}$ to $1.25 \times 10^{-2}$ and almost no $\alpha$ maters were observed. Thus a difference is observed between the appearance of maters on solid medium and in liquid medium, and between the ratio of a maters to $\alpha$ maters with the two methods. In addition considerable variation is observed among experiments carried out under apparently identical conditions.

\subsection{Microdissection and analysis of strain $A$}

CHRISTENSEN (7) has sporulated strain A which yielded asci containing 1 to 4 spores. The 4-spored asci constituted $40 \%$ of the total. Hundred ninety asci with 4 spores were dissected and 317 spores germinated (42\%). In only 4 asci all 4 spores were viable. These 16 spores will hereafter be referred to as the 4 tetrads. Two hundred eighty-four spore clones were analysed of which 111 were found not to sporulate. Of these, 92 were characterized as having the mating type $a$, while 14 were found to have the $\alpha$ mating type (7). The remaining 173 sporulating clones were not further characterized.

In this study all 284 spore clones were retested for growth requirements, mating type and sporulation.

Three of the clones had a requirement for adenine and turned out to be ade 3 mutants. The occurrence of these allelic mutants shows heterozygosity for an ade3 mutation. Since the ade 3 mutant allele segregated with a low frequency it can be assumed that strain $A$ has more than two copies of chromosome VII, unless there is a recessive lethal mutation linked to the ade3 allele.

A summary of the encountered combinations of mating types and sporulation ability is listed in Table IV. Mating was tested after 2 and 5 days of growth in order to allow detection of

Table IV.

Summary of sporulation and mating types of clones derived from dissected spores of strain $A$

\begin{tabular}{lll}
\hline Sporulation & Mating type & Sum \\
\hline- & - & 1 \\
- & $\alpha$ & 15 \\
- & 94 \\
- & weak bisexual & 1 \\
\hline+ & - & 27 \\
+ & $\alpha$ & 70 \\
+ & bisexual & 57 \\
+ & a & 19 \\
\hline
\end{tabular}


Table V.

Stability of mating and sporulation ability of 4 spore-derived strains

\begin{tabular}{|c|c|c|c|c|c|}
\hline Strain & Subclone & $\begin{array}{l}\text { Sporu- } \\
\text { lation }\end{array}$ & $\begin{array}{l}\% \text { of cells } \\
\text { sporulated }\end{array}$ & $\begin{array}{l}\text { Number of } \\
\text { spores in } \\
\text { most of } \\
\text { the asci }\end{array}$ & $\begin{array}{l}\text { Mating } \\
\text { type }\end{array}$ \\
\hline \multirow[t]{2}{*}{$A_{277}$} & 1 & + & 20 & 3 & - \\
\hline & 2 & + & 10 & 2 & - \\
\hline \multirow{5}{*}{$\begin{array}{l}\text { (Non-mater, } \\
\text { sporulator) }\end{array}$} & 3 & - & & & - \\
\hline & 4 & + & 20 & 3 & - \\
\hline & 5 & - & & & - \\
\hline & 6 & + & $20^{x}$ & - & - \\
\hline & 7 & + & $<1^{x}$ & - & - \\
\hline \multirow[t]{2}{*}{$A_{280}$} & 1 & + & 50 & 3 & $\alpha$ \\
\hline & 2 & + & 50 & 3 & - \\
\hline \multirow{5}{*}{$\begin{array}{l}\text { (Non-mater, } \\
\text { sporulator) }\end{array}$} & 3 & + & 60 & 3 & - \\
\hline & 4 & + & 50 & 3 & - \\
\hline & 5 & + & 50 & 3 & $a$ \\
\hline & 6 & + & 60 & 3 & - \\
\hline & 7 & + & 60 & 3 & - \\
\hline \multirow[t]{2}{*}{$A_{32 s}$} & 1 & + & $2^{x}$ & - & a \\
\hline & 2 & + & $2^{x}$ & - & a \\
\hline \multirow{5}{*}{$\begin{array}{l}\text { (Non-mater, } \\
\text { sporulator) }\end{array}$} & 3 & + & 20 & 4 & - \\
\hline & 4 & + & $1^{x}$ & - & a \\
\hline & 5 & + & $2^{x}$ & - & - \\
\hline & 6 & + & $1^{x}$ & - & $\mathbf{a}$ \\
\hline & 7 & + & 10 & 3 & a \\
\hline \multirow[t]{2}{*}{$A_{318}$} & 1 & + & $<1^{x}$ & - & $\alpha$ \\
\hline & 2 & + & $1^{x}$ & - & - \\
\hline \multirow{5}{*}{$\begin{array}{l}\text { (Non-mater, } \\
\text { sporulator) }\end{array}$} & 3 & + & $5^{x}$ & - & - \\
\hline & 4 & + & $10^{x}$ & - & - \\
\hline & 5 & + & $1^{x}$ & - & $\alpha$ \\
\hline & 6 & - & & & $\alpha$ \\
\hline & 7 & + & $2^{x}$ & - & - \\
\hline
\end{tabular}

"The spores were incompletely developed

weak mating type expression. Temperature sensitivity of sporulation was tested by growth on sporulation medium at $10^{\circ} \mathrm{C}$ (after 14 days), $20{ }^{\circ} \mathrm{C}$ (after 7 days), $30^{\circ} \mathrm{C}$ and $37^{\circ} \mathrm{C}$ (both after 5 days). Among strains found to sporulate, some sporulated at all four temperatures, while others sporulated only at $20{ }^{\circ} \mathrm{C}$ and/or $30^{\circ} \mathrm{C}$. All showed maximum sporulation at $20^{\circ} \mathrm{C}$ or $30{ }^{\circ} \mathrm{C}$. It is noticeable that many strains both sporulate and exhibit one or both mating types.

Two spore clones, $A_{146}$ and $A_{343}$, were sporulated and microdissected. Sporulation was more than $95 \%$ in both strains and the asci contained predominantly 4 spores. From each strain 15 4-spored asci were dissected but the spores did not germinate.

The stability of the mating type and the sporulation ability of four strains classified as sporulating non-maters were investigated and the results are listed in Table V. Seven colonies were isolated from each strain and tested. It was found that some of these subclones differed from the mother clones, both with respect to mating type and sporulation. Thus mating type expression and sporulation ability of the spore-derived clones are highly variable traits.

The 16 strains from the four tetrads were investigated for mating ability as described in 
Table VI.

Mating type of 16 spore-derived strains according to the procedures described in sections 2.4 .3 and 2.4.4.

\begin{tabular}{|c|c|c|}
\hline Strain & $\begin{array}{l}\text { Mating type } \\
\text { potential } \\
\text { when tested } \\
\text { in liquid } \\
\text { medium }\end{array}$ & $\begin{array}{l}\text { Mating type } \\
\text { potential } \\
\text { when tested } \\
\text { on solid } \\
\text { medium }\end{array}$ \\
\hline$A_{211}$ & $\mathrm{~nm}$ & $\mathrm{~nm}$ \\
\hline$A_{212}$ & $\mathrm{~nm}$ & $\mathrm{~nm}$ \\
\hline$A_{213}$ & $\alpha$ & $\mathrm{nm}$ \\
\hline$A_{214}$ & $\mathbf{a}$ & $\mathbf{a}$ \\
\hline$A_{277}$ & $\mathrm{~nm}$ & bs \\
\hline $\mathbf{A}_{278}$ & $\alpha$ & $\mathrm{nm}$ \\
\hline$A_{279}$ & $\mathbf{a}$ & $\mathbf{a}$ \\
\hline $\mathbf{A}_{280}$ & $\alpha$ & $\mathrm{nm}$ \\
\hline$A_{325}$ & $\alpha$ & bs \\
\hline$A_{326}$ & $\mathbf{a}$ & $\mathbf{a}$ \\
\hline$A_{327}$ & $\mathrm{~nm}$ & $\mathrm{~nm}$ \\
\hline$A_{328}$ & $\mathrm{~nm}$ & $\mathrm{~nm}$ \\
\hline $\mathbf{A}_{353}$ & $\mathrm{~nm}$ & $\mathrm{~nm}$ \\
\hline $\mathbf{A}_{354}$ & $\alpha$ & bs \\
\hline$A_{3 s s}$ & $\mathbf{a}$ & $\mathbf{a}$ \\
\hline$A_{356}$ & $\alpha$ & $\mathrm{nm}$ \\
\hline
\end{tabular}

section 2.4.4. The results are listed in Table VI. Some lines (e.g. $\mathrm{A}_{214}, \mathrm{~A}_{279}$ ) displayed the a mating type on both media. Mating type a was only expressed in liquid medium (e.g. $A_{213}, A_{278}$ ). Some of the non-maters and $\alpha$ lines identified in liquid medium turned out to be bisexual on solid medium, i.e. they had a potential to become either a or $\boldsymbol{\alpha}$.

\subsection{Analysis of spore-derived strains by crossing and tetrad analysis}

3.5.1. $A_{91} \times N 248-1 A, A_{209} \times N 248-1 C$

In an attempt to determine if strain $A$ is polyploid and the spore-derived strains diploid or aneuploid, crosses were made between sporederived strains and genetically marked haploid strains. The mating products were sporulated, and tetrad analyses performed (18). Such analyses have previously been used to determine the ploidy level of yeast strains $(12,39)$. In addition, they can be used to reveal reduced levels of recombination between chromosomes from the industrial yeast and the standard strains of yeast (33). The segregation patterns in tetrads of a polyploid strain might also demonstrate preferential pairing of chromosomes and could indicate structural differences between the homeologous chromosomes from the industrial yeast and the tester yeast, too small to affect recombination (24).

The mating types of N248-1A and N248-1C are a and $\alpha$, respectively. The $M A T$ locus is located $25 \mathrm{cM}$ from the centromere of chromosome III. Both N248-1A and N248-1C have the genotype met 14 trpl ura3 leul adel his2. The first five mutations are all centromere linked and located on chromosomes XI, IV, V, VII

Table VII.

Analysis of tetrad types in the cross $A_{91} \times$ N248-1A $(M A T a)$

\begin{tabular}{|c|c|c|c|c|c|}
\hline & \multicolumn{5}{|c|}{ segregation } \\
\hline & $+:-$ & $+:-$ & t:- & $+:-$ & $+:-$ \\
\hline & $2: 2$ & $0: 4$ & $1: 3$ & $3: 1$ & 4:0 \\
\hline met & 4 & 0 & 0 & 0 & 13 \\
\hline $\operatorname{trp}$ & 17 & 0 & 0 & 0 & 0 \\
\hline ura & 5 & 0 & 0 & 3 & 9 \\
\hline leu & 5 & 0 & 0 & 0 & 12 \\
\hline ade & 1 & 0 & 0 & 1 & 15 \\
\hline his & 5 & 0 & 0 & 5 & 7 \\
\hline \multicolumn{6}{|c|}{ Mating type segregation } \\
\hline $\mathrm{a}: 3 \alpha$ & $\mathbf{a}: 2 \alpha: \mathbf{a \alpha}:$ & $\alpha: 3 \mathbf{a} \alpha$ & $2 \mathbf{\alpha}: \mathbf{2} \mathbf{a} \alpha$ & 3a:a $\alpha$ & $4 \alpha$ \\
\hline 1 & 3 & 1 & 4 & 6 & 2 \\
\hline
\end{tabular}


Table VIII.

Analysis of tetrad types in the cross $A_{209} \times$ N248-1C $(M A T \alpha)$

\begin{tabular}{|c|c|c|c|c|c|c|c|}
\hline & & & seg & & & & \\
\hline & +:- & t:- & $+:-$ & $+:$ & & t:- & \\
\hline & $2: 2$ & $0: 4$ & $1: 3$ & $3: 1$ & & $4: 0$ & \\
\hline met & 10 & 0 & 0 & 2 & & 20 & \\
\hline trp & 7 & 0 & 1 & 2 & & 22 & \\
\hline ura & 8 & 0 & 0 & 6 & & 18 & \\
\hline leu & 7 & 0 & 0 & 1 & & 24 & \\
\hline ade & 1 & 0 & 0 & 4 & & 27 & \\
\hline his & 3 & 0 & 0 & 10 & & 19 & \\
\hline Matin & gregation & & & & & & \\
\hline $2 \mathbf{a}: 2 \alpha$ & $a: 2 \alpha: a \alpha$ & $a: 3 a$ & $\mathbf{a}: \alpha: 2 \mathbf{a} \alpha$ & $2 \alpha: 2 a \alpha$ & $3 \alpha: a \alpha$ & & $42 a$ \\
\hline 4 & 5 & 2 & 2 & 14 & 2 & & 3 \\
\hline
\end{tabular}

and $\mathrm{I}$, respectively. The mutation $h i s 2$ is located on chromosome VI, $21 \mathrm{cM}$ from the centromere.

The tetrads obtained are listed in Tables VII and VIII. The markers leul, ura3 and met 14 behaved alike in both crosses as did trpl in the cross $A_{209} \times$ N248-1C. In most of the tetrads, these four genes segregated $2: 2$ or 4:0, with respect to wild type spores and mutant spores. The 4:0 tetrads formed a majority. A few or none of the tetrads segregated $3: 1$. In the cross $A_{91} \times N 248-1 A$ the trpl gene segregated exclusively $2: 2$. The marker adel behaved differently from the other centromere markers in that both $3: 1$ and $2: 2$ segregations are observed rarely and the majority of the tetrads segregated 4:0. In the cross $\mathrm{A}_{91} \times \mathrm{N} 248-1 \mathrm{~A}$ HIS2/his 2 segregated $2: 2,3: 1$ and $4: 0$ in almost equal number, whereas in the cross $\mathrm{A}_{209} \times \mathrm{N} 248-1 \mathrm{C}$ HIS2/his2 segregated 4:0 and 3:1 in an almost equal number of tetrads and in the remaining fewer tetrads the marker segregated 2:2. More 3:1 segregations were seen for this marker than for the other markers in agreement with the expectation since this is not a closely centromere linked marker.

For most of the markers a remarkably large fraction of the tetrads segregated $4: 0$, the only exception being the segregation of $t r p l$ in the cross $A_{91} \times N 248-1 A$ where regular 2:2 segregation is observed. Judging from these findings it appears most likely that $A_{91}$ and $A_{209}$ contain two copies of each of the chromosomes $I, V$, VI, VII and XI. In addition $A_{209}$ probably contains two copies of chromosome IV, whereas $A_{91}$ contains a single chromosome IV. A struc-

Table IX.

Expected percentage of genotypes and phenotypes of $M A T$ in the 4 tetrad types found after sporulation of a MATa MATa MAT $\alpha$ trisomic strain (41)

\begin{tabular}{lllll}
\hline Genotypes & $M A T \mathbf{a} M A T \mathbf{a}$ & $M A T \mathbf{a} M A T \mathbf{a}$ & $M A T \mathbf{a} M A T \mathbf{a}$ & $M A T \mathbf{a} M A T \alpha$ \\
& $M A T \mathbf{a} M A T \mathbf{a}$ & $M A T \mathbf{a} M A T \alpha$ & $M A T \alpha M A T \alpha$ & $M A T \mathbf{a} M A T \alpha$ \\
& $M A T \mathbf{\alpha}$ & $M A T \mathbf{\alpha}$ & $M A T \mathbf{a}$ & $M A T \mathbf{a}$ \\
& $M A T \mathbf{\alpha}$ & $M A T \mathbf{a}$ & $M A T \mathbf{a}$ & $M A T \mathbf{a}$ \\
Phenotypes & $\mathbf{a}$ & $\mathbf{a}$ & $\mathbf{a}$ & $\mathrm{nm}^{\mathrm{x}}$ \\
(Mating types) & $\mathbf{a}$ & $\mathrm{nm}^{\mathrm{x}}$ & $\alpha$ & $\mathrm{nm}^{\mathrm{x}}$ \\
& $\alpha$ & $\alpha$ & $\mathbf{a}$ & $\mathbf{a}$ \\
& $\alpha$ & $\mathbf{a}$ & $\mathbf{a}$ & $\mathbf{a}$ \\
& $21 \%$ & $24 \%$ & $6 \%$ & $48 \%$ \\
\hline
\end{tabular}

${ }^{x}$ Either non-maters or bisexual due to chromosome loss. 
tural difference between the chromosomes of the distiller's yeast and those of the tester strains is indicated by the observation that a larger part of the tetrads segregated 4:0 than expected for random disjunction in a cross of the type $+1+$ $x-(37,41)$. This can be due to a preferential pairing of the chromosomes originating from the industrial strain, vs. pairing of chromosomes from the industrial strain and the tester strain, analogous to what has been observed by $\mathbf{J}_{\text {AMES }}$ and INHABER (24).

With respect to the mating type the two crosses showed quite different segregation patterns, but both indicate that neither $A_{91}$ nor $A_{209}$ are monosomic for chromosome III. As $A_{91}$ and $A_{209}$ are disomic for several chromosomes the possibility exists that these strains are disomic for chromosome III as well, in spite of the fact that they express mating type. The segregation expected for a cross between a strain disomic for chromosome III, with the genotype $M A T \mathbf{a}$ $M A T \mathbf{a}$, and a haploid strain, $M A T \alpha$, is listed in Table IX. The results from the two crosses were not in agreement with such a segregation. Several explanations can be proposed: Some mating type genes may not be expressed, chromosomes may be lost during meiosis or the gene for homothallism causes the mating types to shift.

\subsubsection{Indication of presence of ade 3 in $A_{91}$}

Two crosses between $A_{91}$ and N248-1A were made. The first one being described in section 3.5.1 was started with many cells which were made respiratory deficient and then crossed. In the second cross $A_{91} \times$ N248-1 A which started from a single cell the spore viability was for some unknown reason very low (about $0.1 \%$ ) in contrast to that found in the first cross (about $70 \%$ ). Twelve spore-derived strains were obtained by streaking sporulated cells on YPD and they were tested for mitotic stability by subcloning. Eleven strains were found to be stable whereas the twelfth strain was not. Out of a hundred subclones of this spore-derived strain (KK137, $\alpha$ prototroph) one had a histidine requirement (his2) and seven were auxotrophic for methionine (met 14). One of these methionine auxotrophs, KK146, was further subcloned. One out of thousand subclones was of the phenotype MATa met14 ade3, KK147. Strain N248-1A is known to be haploid and does not show an ade 3 phenotype, i.e. the colonies are red depending on the presence of adel. The most likely explanation for the presence of ade3 in KK 147 is that $A_{91}$ is disomic for chromsome VII and that it is heterozygous for ade 3 .

\subsection{Molecular characterization of strain $A$ and its meiotic segregants}

3.6.1. Determination of nucleotide sequences of chromosomes in strain $A$ in comparison with genetic standard strains

A molecular characterization of strain A might provide information about its genetic constitution, which is otherwise difficult to obtain. Nucleotide sequence divergences from the standard strains of yeast genetics can be revealed. Chromosome III was chosen for analysis because of the presence of the mating type locus $(M A T)$ as a good knowledge of this gene is of importance for future breeding. In addition to the $M A T$ locus, chromosome III contains the $H I S 4$ and the LEU2 genes as well as two silent mating type loci ( $H M L$ and $H M R$ ). Strain A as well as the 16 spore-derived strains from the 4 tetrads described earlier (section 3.4) were investigated in all these regions. Gel electrophoresis was performed on genomic DNA which was digested with restriction endonucleases. The DNA was transferred from the gels to nitrocellulose filters according to SOUTHERN (44) and subjected to hybridization with a ${ }^{32} \mathrm{P}$-labelled plasmid or DNA fragment containing the gene or part of the gene in question.

\subsubsection{Molecular analysis of the HIS4 region}

Hybridization was carried out with plasmid pC503 as the probe. This plasmid contains a $9.4 \mathrm{~kb}$ Pst fragment from $S$. cerevisiae including the HIS4 gene (22). The isolated total genomic DNA was digested with restriction endonucleases EcoRI, PstI, BamHI, HindIII, SalI, HpaI, MboI and PvuII. For all enzymes both strain $\mathrm{A}$ and its meiotic products gave band patterns identical to that of $\mathrm{S}$. cerevisiae strain $\mathrm{S} 288 \mathrm{C}$ 

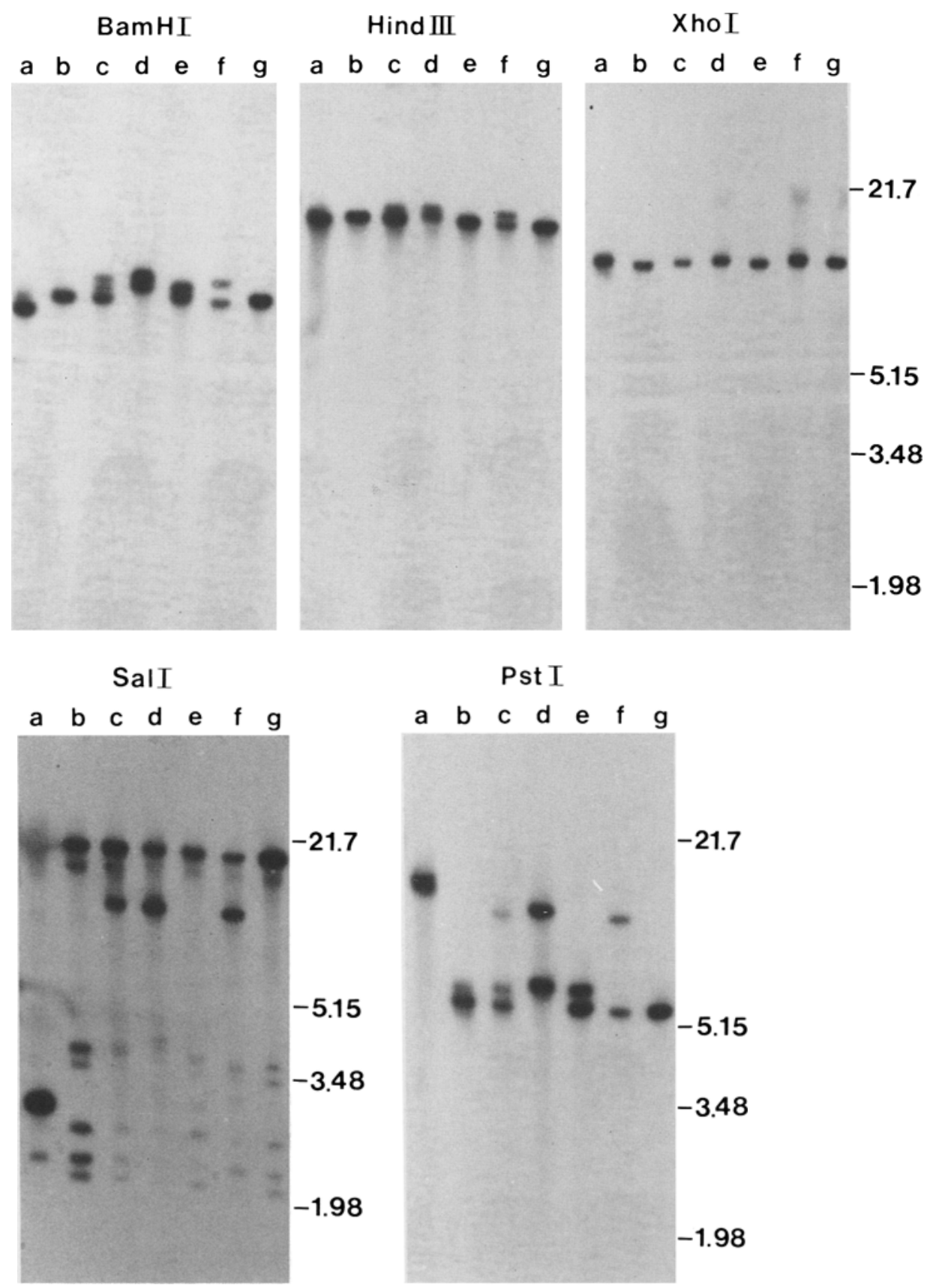

Figure 2a. Restriction endonuclease fragment analysis of the $L E U 2$ region in strain $\mathrm{A}$ and its 4 meiotic products $A_{211}-A_{214}$. DNA from strains S288C (a), A9275C (b), A (c) and $A_{211}-A_{214}(d-g)$ were cleaved with BamHI, HindIII, Xhol, Sall and Pstl, subjected to electrophoresis in $0.7 \%$ agarose and transferred to a nitrocellulose filter. The DNA was hybridized to a ${ }^{32} \mathrm{P}$-labelled $830 \mathrm{bp}$ EcoRI-Sall fragment containing part of the $L E U 2$ gene, cloned from $\mathrm{S}$. cerevisiae. Sizes are stated in $\mathrm{kb}$. 


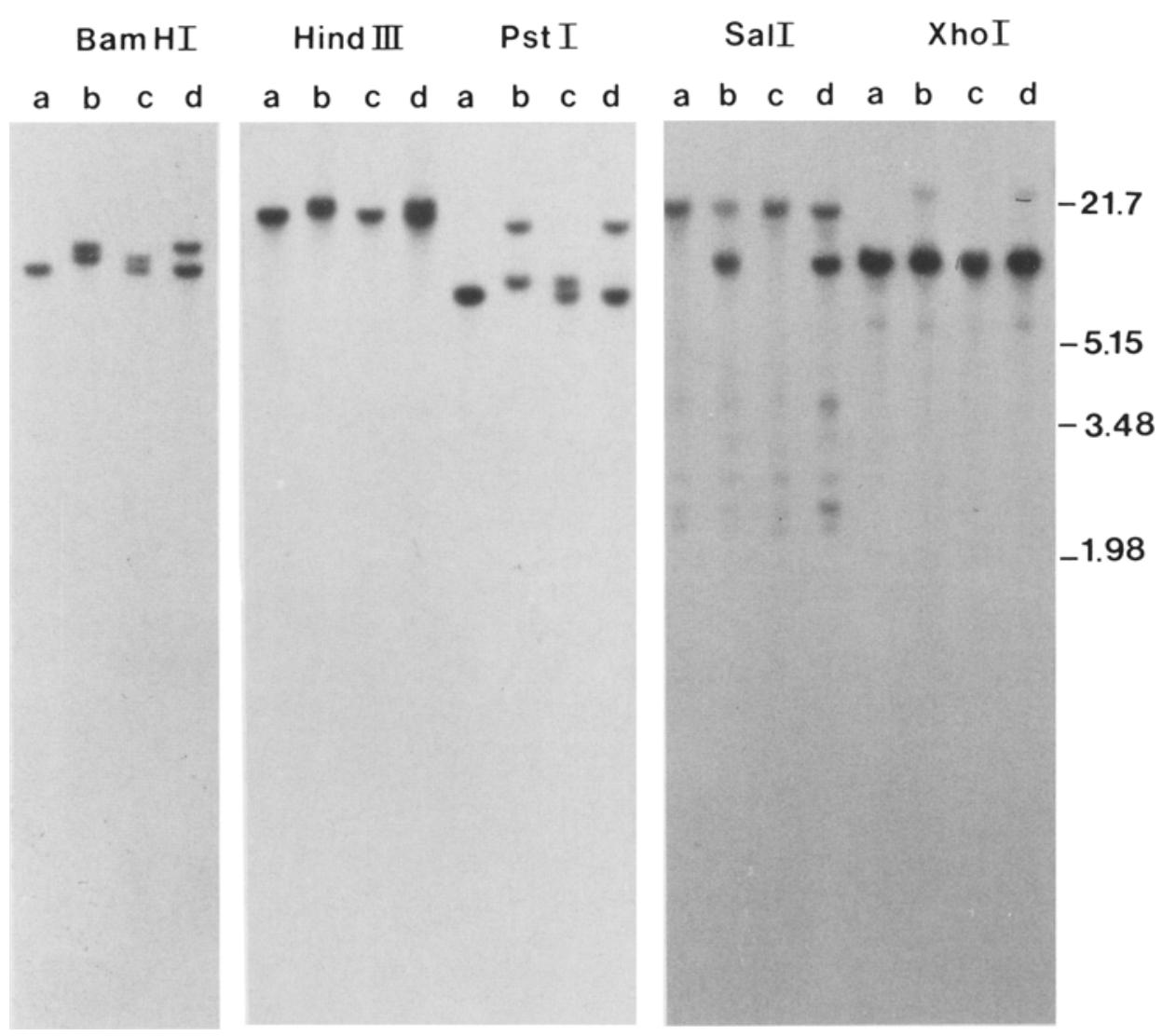

Figure 2b. Restriction endonuclease fragment analysis of the LEU2 region in the 4 meiotic products $\mathrm{A}_{277}-$ $A_{280}$. Sizes are stated in $\mathrm{kb}$. (a) $\mathrm{A}_{277}$, (b) $\mathrm{A}_{278,}$, (c) $\mathrm{A}_{279}$, (d) $\mathrm{A}_{280}$.

(33) (results not shown). Thus, the nucleotide sequences in the HIS4 region of $\mathrm{S} 288 \mathrm{C}$ and strain A are similar.

\subsubsection{Molecular analysis of the LEU2 region}

Hybridization was carried out with a $830 \mathrm{bp}$ EcoRI-Sall fragment containing part of the $L E U 2$ gene from S. cerevisiae as the probe. This fragment has been isolated from plasmid pYF91.2 (45). The total DNA was digested with restriction endonucleases BamHI, HindIII, XhoI, SalI, PstI and EcoRI. The hybridization patterns obtained from strains S288C, A9275C, $A$ and the meiotic segregants $A_{211}, A_{212}, A_{213}$ and $A_{214}$ are shown in Figure 2a. All patterns obtained from strain S288C (lanes a) are in agreement with previous observations $(6,9,45)$. The restriction map of $L E U 2$ and the surrounding regions in $\mathrm{S} 288 \mathrm{C}$ are shown in Figure 3. These regions include a $t R N A_{3}^{\text {leu }}$ gene and a $T y$ element.

The hybridization patterns obtained in XhoI digests were similar for all strains investigated. The Xhol fragment of S288C hybridizing to the probe used is known to cover part of the $\delta$ sequence, the entire $t R N A$ gene and the entire $L E U 2$ gene (45). Also the EcoRI fragments (not shown) of strains S288C and A were indistinguishable. The EcoRI fragment hybridizing to the probe used is known to cover the centromere-proximal part of the LEU2 gene (6). With the other enzymes, the hybridizing fragments are known to have one of their endpoints either inside the $T y$ element or centromere-distal to this $(6,45)$.

The same general type of hybridization pat- 


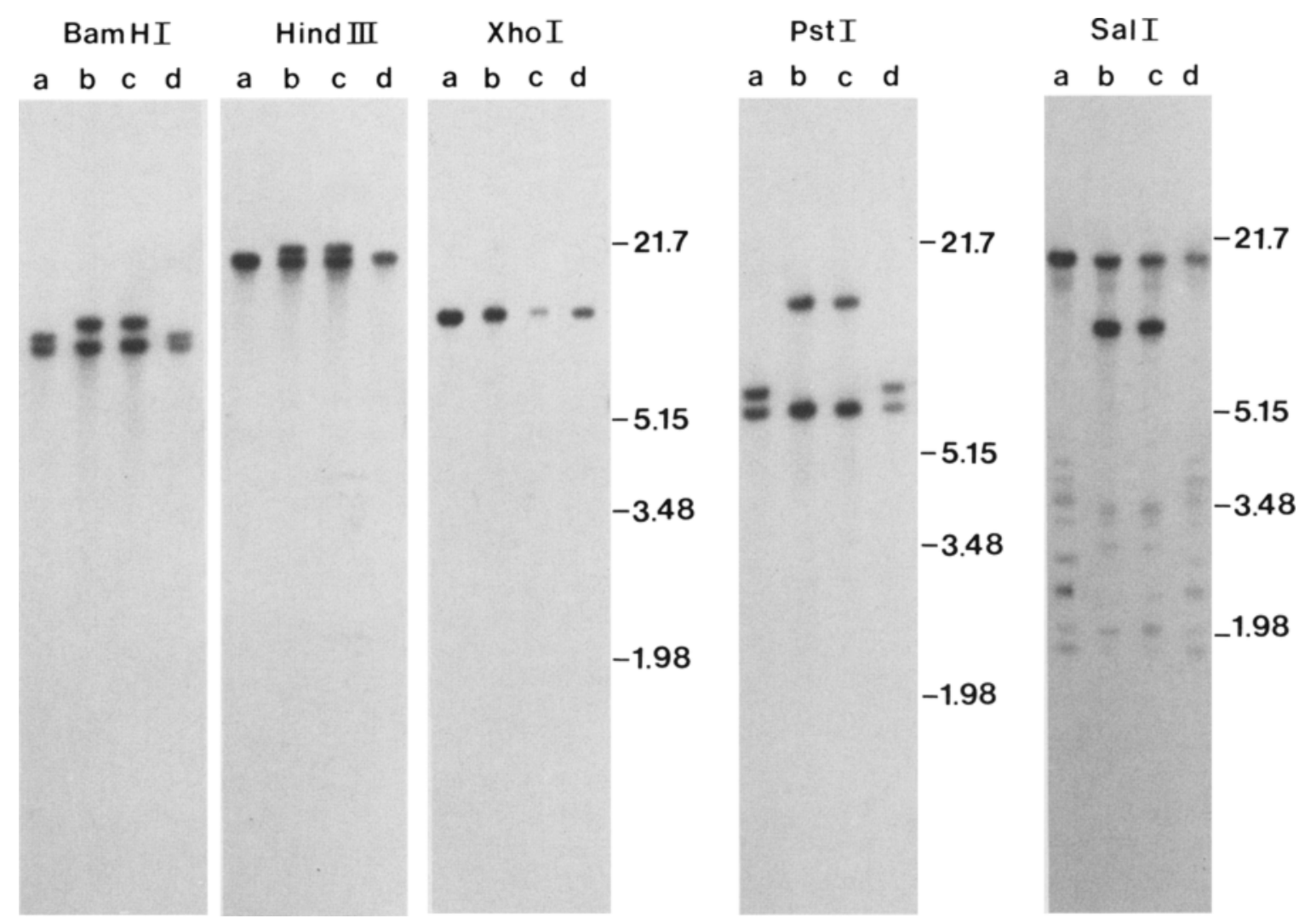

Figure 2c. Restriction endonuclease fragment analysis of the $L E U 2$ region in the 4 meiotic products $A_{325}-$ $A_{328}$. Sizes are stated in $k b$. (a) $A_{325}$, (b) $A_{326}$, (c) $A_{327}$, (d) $A_{328}$.

terns was seen when BamHI, HindIII and PstI digests of DNA from strain A were hybridized to the LEU2 probe: Three hybridizing bands were observed. The fastest migrating band results from the shortest fragment. This band showed a stronger hybridization intensity than the two other bands. This indicates either that this fragment is present twice or the hybridization of the two other fragments to the probe is weaker due to reduced homology. An independent segregation of the bands was found in the four meiotic products. Three of the strains $\left(A_{211}, A_{212}, A_{213}\right.$, lanes d,e,f) contained two bands, the fourth strain $\left(A_{214}\right.$, lanes $g$ ) contained only one band which hybridized strongly. By assuming that this band contains twice the amount of DNA (e.g. the strain contains two copies of the gene) it can be seen that the four bands had segregated independently. The observed hybri- dization patterns to the two prominent SalI fragments of 8 and $20 \mathrm{~kb}$ from strains $A$ and $A_{211}-A_{214}$ are in agreement with the independent segregation mentioned above. It is assumed that $\mathrm{A}_{212}$ and $\mathrm{A}_{214}$ contain two LEU2 regions with identical restriction sites. The additional bands seen in Figure $2 \mathrm{a}$ in the high and low molecular regions are most likely due to the presence of a contaminating endonuclease activity.

Figures $2 \mathrm{~b}, 2 \mathrm{c}$ and $2 \mathrm{~d}$ show the hybridization patterns of BamHI, HindIII, Xhol, SalI and PstI digests of DNA from the three other tetrads $\left(A_{27}\right.$ $-A_{280}, A_{325}-A_{328}$ and $A_{353}-A_{356}$ ). Similar to strains $A_{211}-A_{214}$, each of these three tetrads shows independent segregation of the hybridizing bands.

Judging from the XhoI and EcoRI digests the restriction site maps proximal of the XhoI site in the $\delta$ region of $T y l-17$ (Figure 3) towards 
A.K. KEIDING: Characterization of distiller's yeast

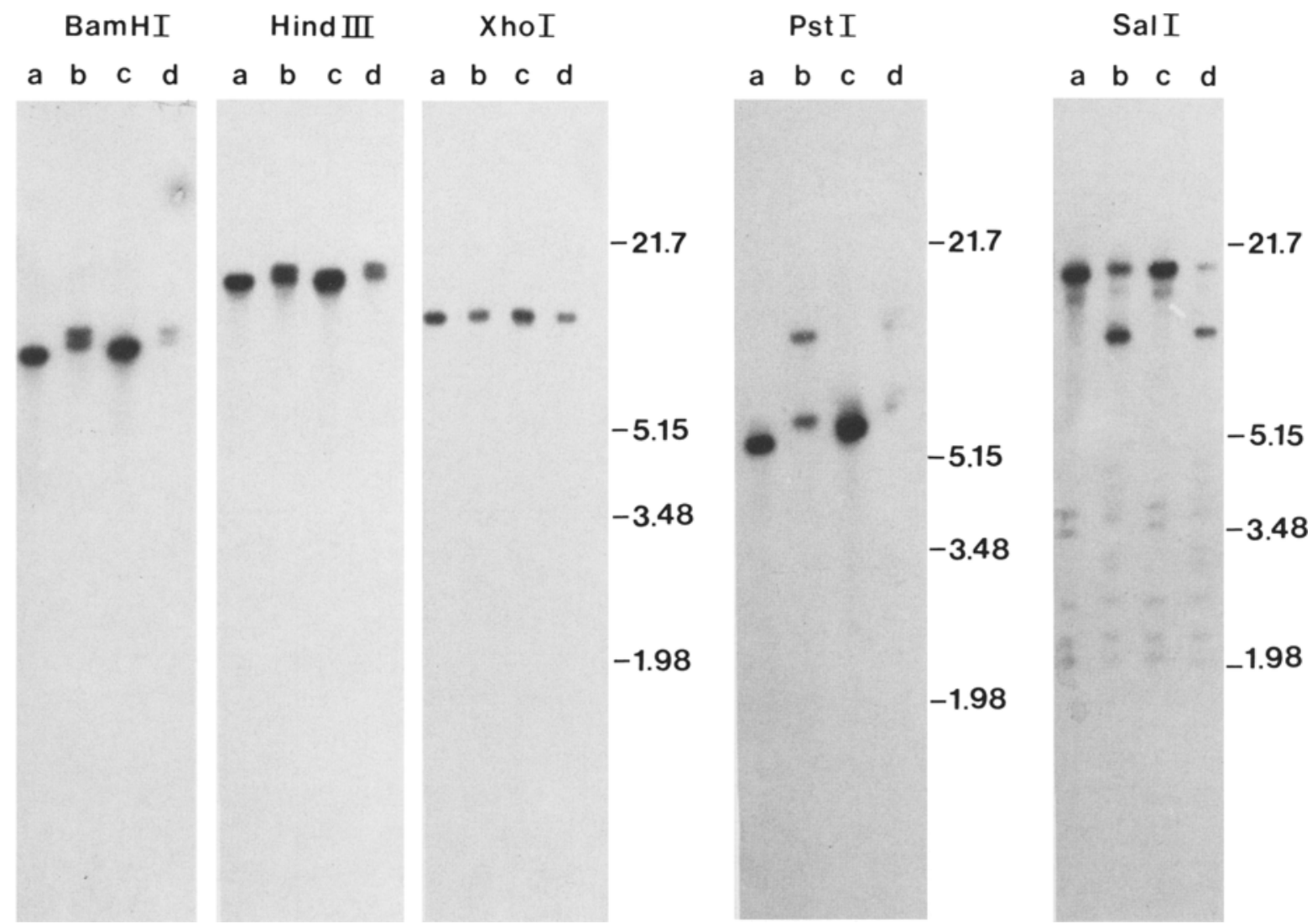

Figure $2 \mathrm{~d}$. Restriction endonuclease fragment analysis of the $L E U 2$ region in the 4 meiotic products $A_{353}-$ $A_{356}$. Sizes are stated in $k b$. (a) $A_{353}$, (b) $A_{344}$, (c) $A_{355}$, (d) $A_{356}$.

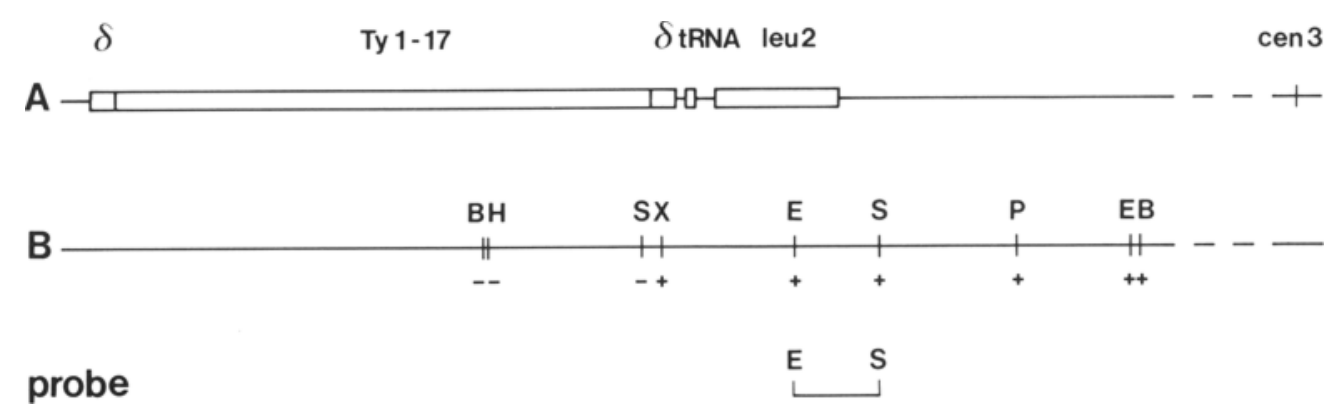

Figure 3. Partial restriction endonuclease site map of the LEU2 region in $\mathrm{S}$. cerevisiae strain $\mathrm{S} 288 \mathrm{C}(9)$ and strain $\mathrm{A}$. Line $\mathrm{A}$ shows the relative location of $L E U 2$, a $t R N A$ gene and $T y /-17$. On line $\mathrm{B}$ relevant restriction sites are indicated. Below line $B$, the sites found to be present $(+)$ or absent $(-)$ in strain $A$ are indicated. The 830 bp EcoRI-Sall fragment is indicated. E - EcoRI, S - SalI, B - BamHI, H - HindIII, X - XhoI, P Pstl. 
Table $X$.

Sizes in kb of restriction endonuclease fragments of $M A T, H M L, H M R$ and $L E U 2$ alleles. Fragment sizes different from $\mathrm{S288C}$ are in italies

\begin{tabular}{|c|c|c|c|c|c|c|c|}
\hline & HindIII & BamHI & PstI & & EcoRI & BglII & HhaI \\
\hline$M A T^{5}$ & $4.3^{4}$ & 13.5 & 8.3 & & 6.7 & & \\
\hline$M A T^{\prime}$ & $4.3^{4}$ & ca. 30 & ca. 11 & & 6.7 & & \\
\hline$M A T^{\prime \prime}$ & $4.3^{4}$ & ca. 22 & 8.3 & & ca. 11 & & \\
\hline$M A T^{\prime \prime \prime}$ & $4.3^{4}$ & ca. 22 & ca. 11 & & 6.7 & & \\
\hline$M A T^{\prime \prime}$ & $4.3^{4}$ & 13.5 & ca. 11 & & 6.7 & & \\
\hline$H M R^{\prime S}$ & 5.0 & 10.5 & 7.2 & & 12 & $8.6 ; 1.4$ & $1.6 ; 0.6$ \\
\hline$H M R^{\prime \prime}$ & 5.0 & 10.5 & 7.2 & & 12 & $8.6 ; 1.5$ & $1.75 ; 0.6$ \\
\hline$H M R^{\prime \prime}$ & ca. 9 & 10.5 & ca. 13 & & ca. 16 & $8.6 ; 7.1$ & $1.95 ; 0.6$ \\
\hline \multirow[t]{2}{*}{$H M L^{5}$} & 6.1 & 6.7 & 5.2 & & 5.2 & & \\
\hline & HindIII & BamHI & Pstl & & EcoRI & SalI & Xhol \\
\hline$\angle E U 2^{5}$ & 14.3 & 6.6 & ca. 16 & & 3.4 & 2 & ca. 8 \\
\hline LEU2' & ca. 17 & ca. 8 & 6.3 & & 3.4 & ca. 20 & ca. 8 \\
\hline$L E U 2^{2}$ & ca. 17 & ca. 8.5 & ca. 7 & & 3.4 & ca. 20 & ca. 8 \\
\hline \multirow[t]{2}{*}{$L E U 2^{3}$} & ca. 19 & ca. 9.5 & ca. 14 & & 3.4 & ca. 8 & ca. 8 \\
\hline & BglII & & Hhal & & & & \\
\hline$M A T \mathrm{a}^{5}$ & $\begin{array}{l}\text { ca. } 20 \\
4.2\end{array}$ & 2.50 & 1.12 & & 0.79 & & \\
\hline$M A T \alpha^{5}$ & ca. 24 & 1.65 & 1.12 & 0.95 & 0.79 & & \\
\hline$H M L a^{5}$ & ca. 14 & 2.2 & & 0.95 & $0.79 ; 0.44$ & & \\
\hline
\end{tabular}

${ }^{4}$ The HindIII fragment of MATa is $4.3 \mathrm{~kb}$, the HindIII fragment of MATa is $4.2 \mathrm{~kb}$.

'The sizes of restriction endonuclease fragments in S288C.

the centromere and including the LEU2 gene were the same in these strains. Furthermore, the hybridizing fragments obtained from the other digests of DNA revealed that there were no new BamHI, HindIII, SalI or PstI sites present in the $L E U 2$ fragment used as a probe. Strain A thus contains four copies of the $L E U 2$ gene exhibiting three different nucleotide sequences centromere-distal from the gene. These are named $L E U 2^{I}$, which is present in two copies, $L E U 2^{2}$ and $L E U 2^{3}$, both present in one copy. The sizes of the hybridization fragments are listed in Table $\mathrm{X}$, the distribution of $L E U 2^{\prime}$, $L E U 2^{2}$ and $L E U 2^{3}$ between the spore-derived strains are listed in Table XI.

3.6.4. Molecular analyses of the mating type MAT, HML and HMR loci

Hybridization was carried out with the plasmid M27I as a probe (21). This plasmid contains a $4.3 \mathrm{~kb}$ HindIII insert covering the entire $M A T \alpha$ gene from $\mathrm{S}$. cerevisiae. The probe also hybridizes to the two silent mating type cassettes. The autoradiograms of genomic DNA of strains S288C, A9275C, A and $A_{211}-A_{214}$ digested with HindIII, BamHI, PstI and EcoRI are shown in Figure 4a, while digests with HhaI and Bglll are shown in Figure 5a.

In all cases DNA from strains $\mathrm{S} 288 \mathrm{C}$ (lanes a) and $\mathrm{A} 9275 \mathrm{C}$ (lanes b) digested with HindIII, BamHI, PstI and EcoRI exhibited the three bands expected from the knowledge of the restriction map of these three loci $(32,46)$. The origin of each band is indicated in Figure 4a. In strain $\mathrm{A}$ (lanes $\mathrm{c}$ ) additional fragments were seen. In the HindIII digest an extra band was seen at approximately $9 \mathrm{~kb}$. With the other enzymes two extra bands were present with sizes of approximately $22 \mathrm{~kb}$ and $30 \mathrm{~kb}$ (BamHI); $11 \mathrm{~kb}$ and $13 \mathrm{~kb}$ (PstI), and $11 \mathrm{~kb}$ and $16 \mathrm{~kb}$ (EcoRI), respectively. These additional frag- 
Table XI.

Distribution of $M A T, M A T \mathrm{a}, M A T a, H M L, H M R$ and $L E U 2$ alleles in the spore-derived strains studied

\begin{tabular}{|c|c|c|c|c|c|c|c|c|c|c|c|c|c|}
\hline & \multicolumn{4}{|c|}{$M A T$} & \multicolumn{2}{|c|}{$M A T \mathbf{a} M A T \alpha$} & \multicolumn{3}{|c|}{$H M R$} & \multirow[t]{2}{*}{$H M L$} & \multicolumn{3}{|c|}{$L E U 2$} \\
\hline & $\mathbf{I}$ & II & III & IV & & & I & II & III & & 1 & 2 & 3 \\
\hline$A_{211}$ & + & & & + & + & + & & + & & + & & + & + \\
\hline$A_{212}$ & + & + & & & + & + & + & & + & + & + & + & \\
\hline$A_{21,3}$ & & + & + & & + & + & & + & & & + & & + \\
\hline $\mathbf{A}_{214}$ & & & + & + & ++ & & + & & + & & ++ & & \\
\hline $\mathbf{A}_{277}$ & + & + & & & + & + & + & & & + & ++ & & \\
\hline$A_{278}$ & & & + & + & + & + & + & & + & + & & + & + \\
\hline $\mathbf{A}_{279}$ & + & + & & & ++ & & & ++ & & & + & + & \\
\hline$A_{280}$ & & & + & + & + & + & & & + & & + & & + \\
\hline$A_{325}$ & & + & & + & + & + & & & + & + & + & + & \\
\hline$A_{326}$ & + & & & + & ++ & & + & + & & & + & & + \\
\hline $\mathrm{A}_{327}$ & + & & + & & + & + & + & + & & & + & & + \\
\hline$A_{328}$ & & + & + & & + & + & & & + & + & + & + & \\
\hline$A_{353}$ & + & + & & & + & + & + & & + & + & ++ & & \\
\hline$A_{354}$ & & & + & + & + & + & & + & & + & & + & + \\
\hline$A_{3 s s}$ & + & + & & & ++ & & & + & + & & ++ & & \\
\hline$A_{356}$ & & & + & + & + & + & + & & & & & + & + \\
\hline \multicolumn{14}{|c|}{ Alternative } \\
\hline$A_{211}$ & & & + & + & + & + & & + & & + & & + & + \\
\hline $\mathbf{A}_{212}$ & + & + & & & + & + & + & & + & + & + & + & \\
\hline$A_{213}$ & & + & + & & + & + & & + & & & + & & + \\
\hline $\mathrm{A}_{2: 4}$ & + & & & + & ++ & & + & & + & & ++ & & \\
\hline
\end{tabular}

Each + represents one copy.

'The distribution of the four $M A T$ versions according to the crossing over assumed in section 3.6.5.

ments could be identified by the segregation in the spore-derived strains (lanes $d, e, f, g$ ) as described below.

$H M R$ is known to hybridize with less intensity to the probe because of less homology. In the spore-derived strains the extra band of the HindIII digest hybridized with the same intensity as the $H M R$ band at $5.0 \mathrm{~kb}$. This is taken to mean that this band covers a $H M R$ gene in strain $A$. The band appeared in two of the sporederived strains, $\mathrm{A}_{212}$ (lane e) and $\mathrm{A}_{214}$ (lane g). Also in the PstI and EcoRI digests bands appeared hybridizing with the same intensity as $H M R$ and again segregation in $\mathrm{A}_{212}$ and $\mathrm{A}_{214}$ was seen. In these three digests the normal $H M R$ bands appeared with equal intensity in all 4 strains, which indicates that one standard copy is present in each strain. Judged by these results it is assumed that three $H M R$ genes are present in strain A. The BamHI digests were in agreement with this hypothesis: No alternative HMR band was found but instead the standard sized $H M R$ fragment appeared with double intensity in $A_{212}$ and $A_{214}$. It can be concluded that two of the $H M R$ genes are similar and result in standard fragments whereas the third $H M R$ gene results in alternative HindIII, PstI and EcoRI fragments.

Segregation of $H M L$ is also demonstrated. In the HindIII digests of both $A_{211}$ (lane d) and $A_{212}$ (lane e) a normal sized fragment originating from $H M L$ is seen whereas in $\mathrm{A}_{213}$ (lane $\mathrm{f}$ ) and $\mathrm{A}_{214}$ (lane $\mathrm{g}$ ) no bands were found which can originate from $H M L$. Thus, none of the additional bands found in the other digests can originate from $H M L$. 

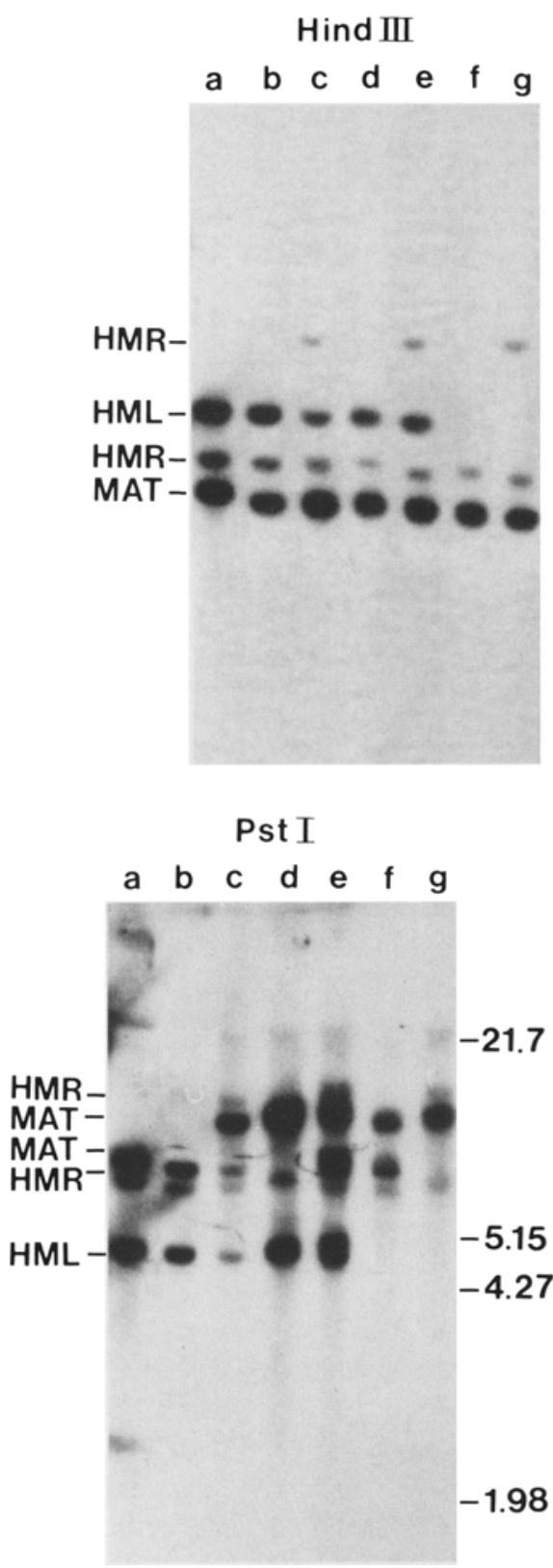
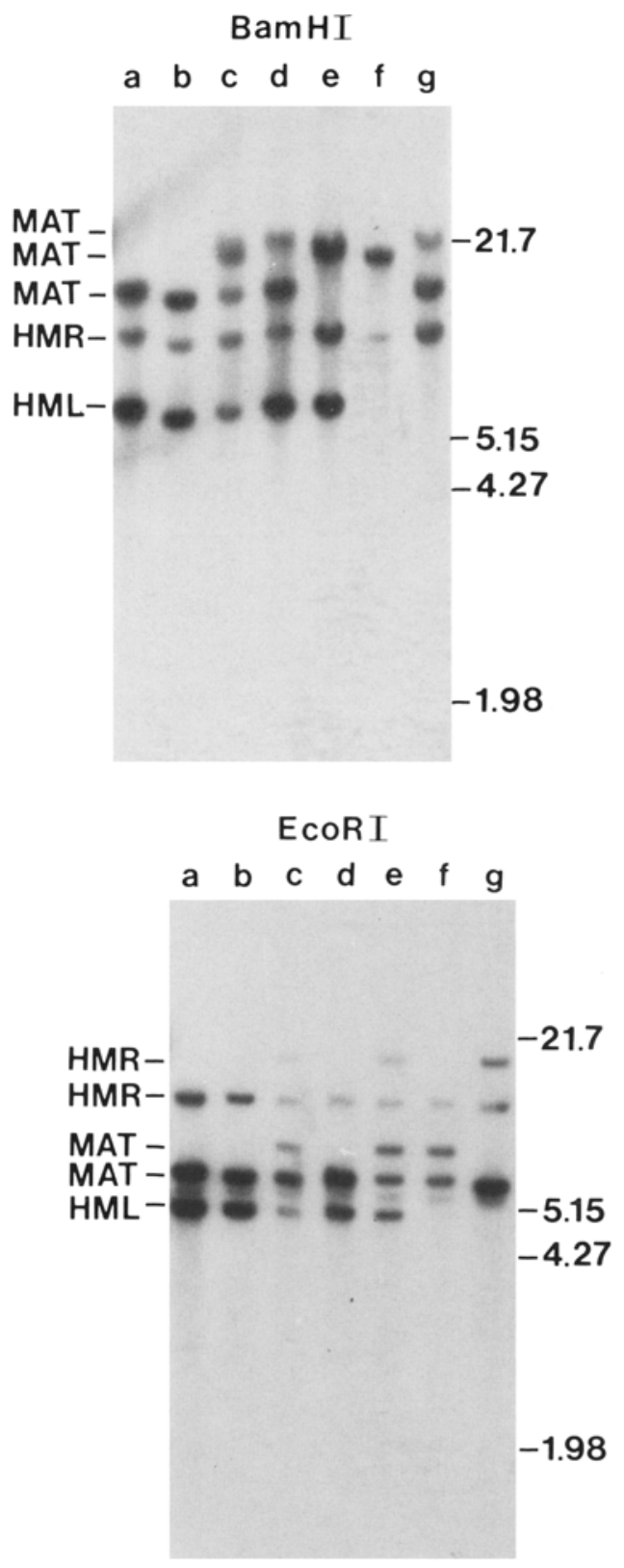

Figure 4a. Restriction endonuclease fragment analysis and identification of $M A T, H M L$ and $H M R$ in strain $A$ and its 4 meiotic products $A_{211}-A_{214}$. DNA from strains $\$ 288 C$ (a), A9275C (b), A (c) and $A_{211}-A_{214}$ (d-g) were cleaved with HindIII, BamHI, PstI and EcoRI, subjected to electrophoresis in $0.7 \%$ agarose and transferred to a nitrocellulose filter. The DNA was hybridized to a ${ }^{32} \mathrm{P}$-labelled plasmid containing a $4.3 \mathrm{~kb}$ HindIII fragment covering the entired $M A T \alpha$ gene, cloned from $\mathrm{S}$. cerevisiae. Sizes are stated in $\mathrm{kb}$.

According to my hypothesis all other extra bands not identified above cover versions of the $M A T$ locus probably diverging from $\mathrm{S} 288 \mathrm{C}$ in the nucleotide sequences flanking $M A T$. In the HindIII digests the probe was found to hybridize only to one fragment covering the $M A T$ locus. 


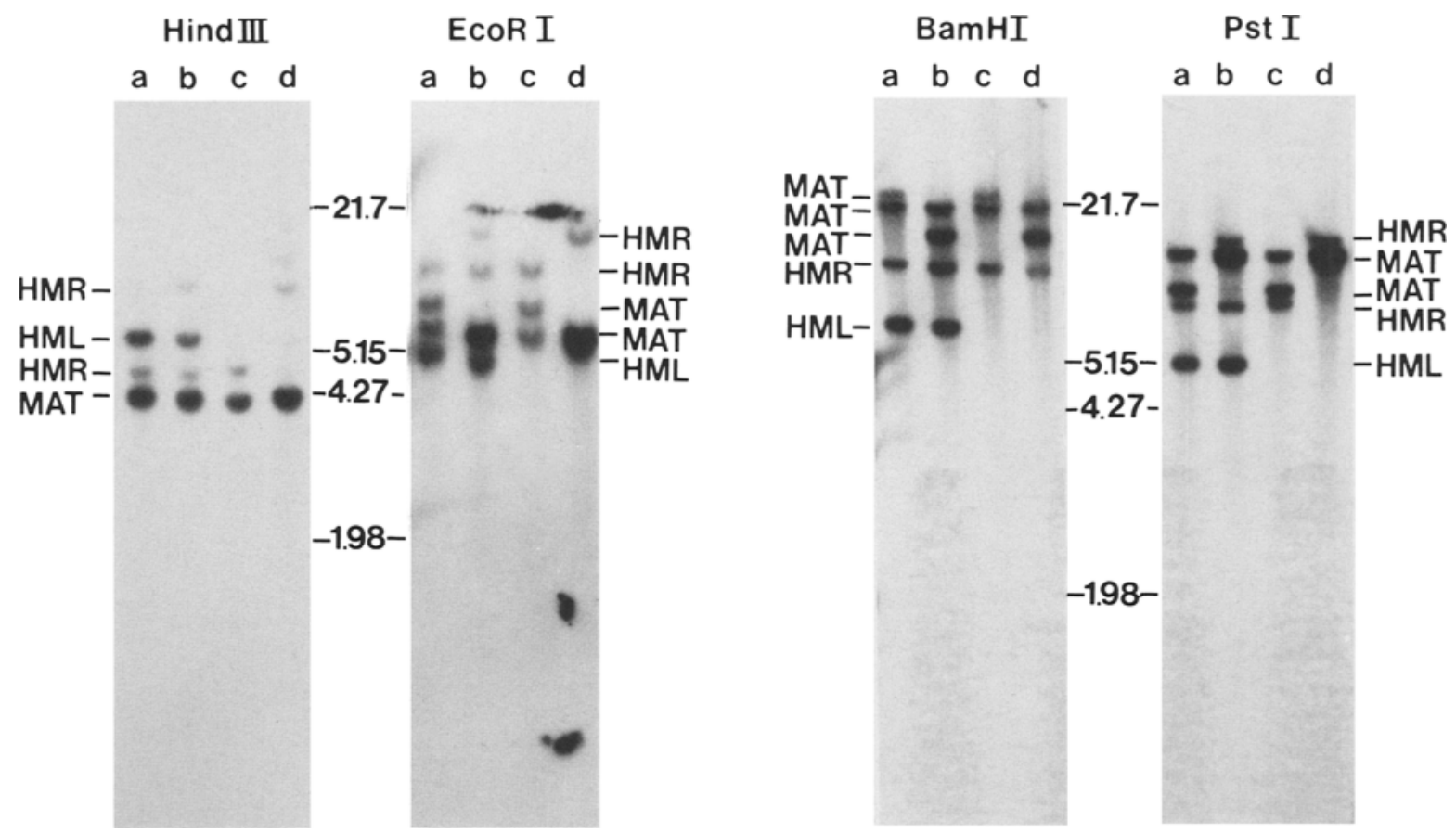

Figure $4 \mathrm{~b}$. Restriction endonuclease fragment analysis and identification of $M A T, H M L$ and $H M R$ in the 4 meiotic products $A_{27}-A_{280}$. Sizes are stated in $k b$. (a) $A_{277}$, (b) $A_{278}$, (c) $A_{279}$, (d) $A_{280}$.

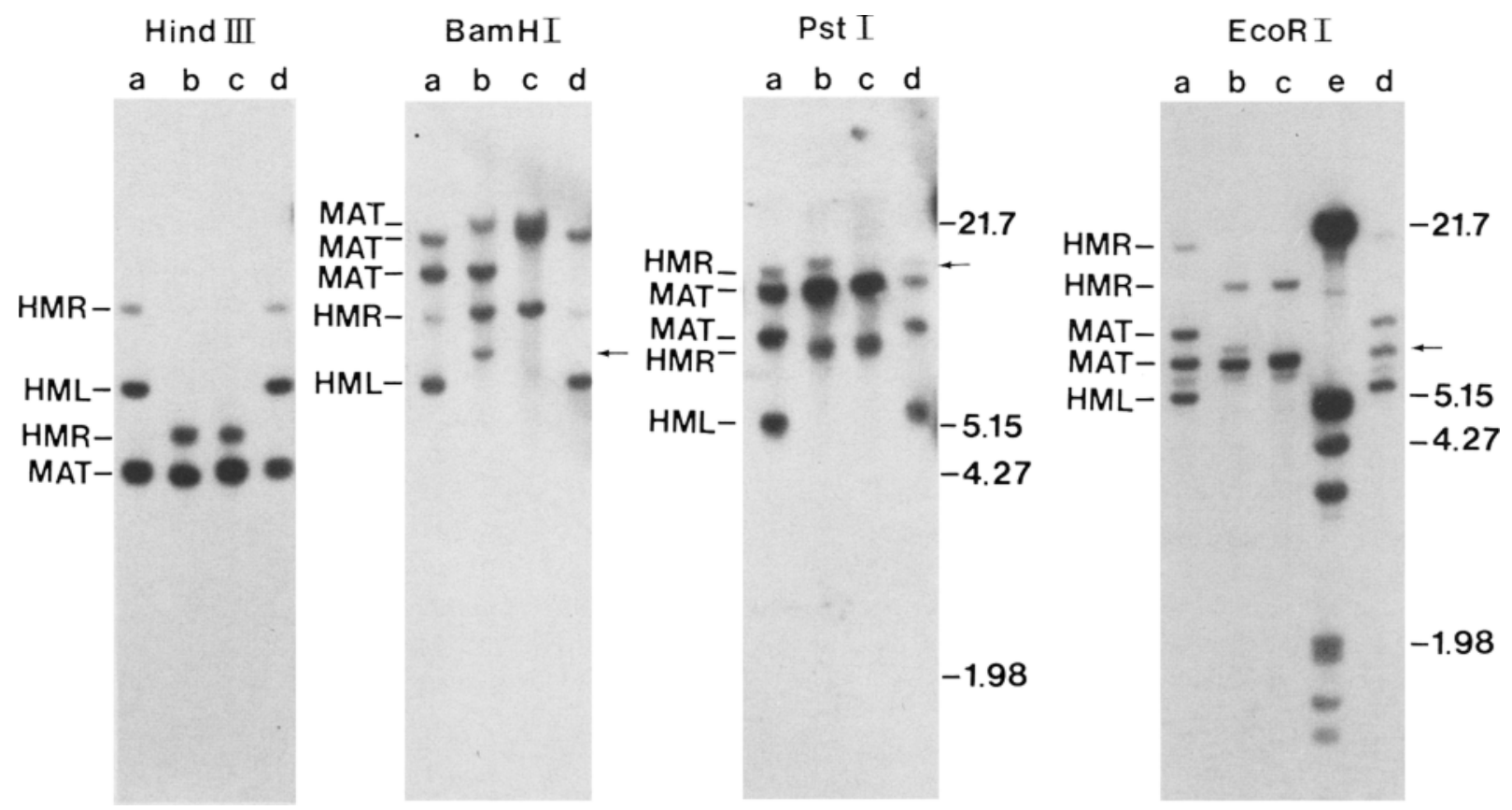

Figure 4c. Restriction endonuclease fragment analysis and identification of $M A T, H M L$ and $H M R$ in the 4 meiotic products $A_{325}-A_{328}$. Sizes are stated in kb. (a) $A_{325}$, (b) $A_{326}$, (c) $A_{327}$, (d) $A_{328}$, (e) $\lambda$ sizemarker. 


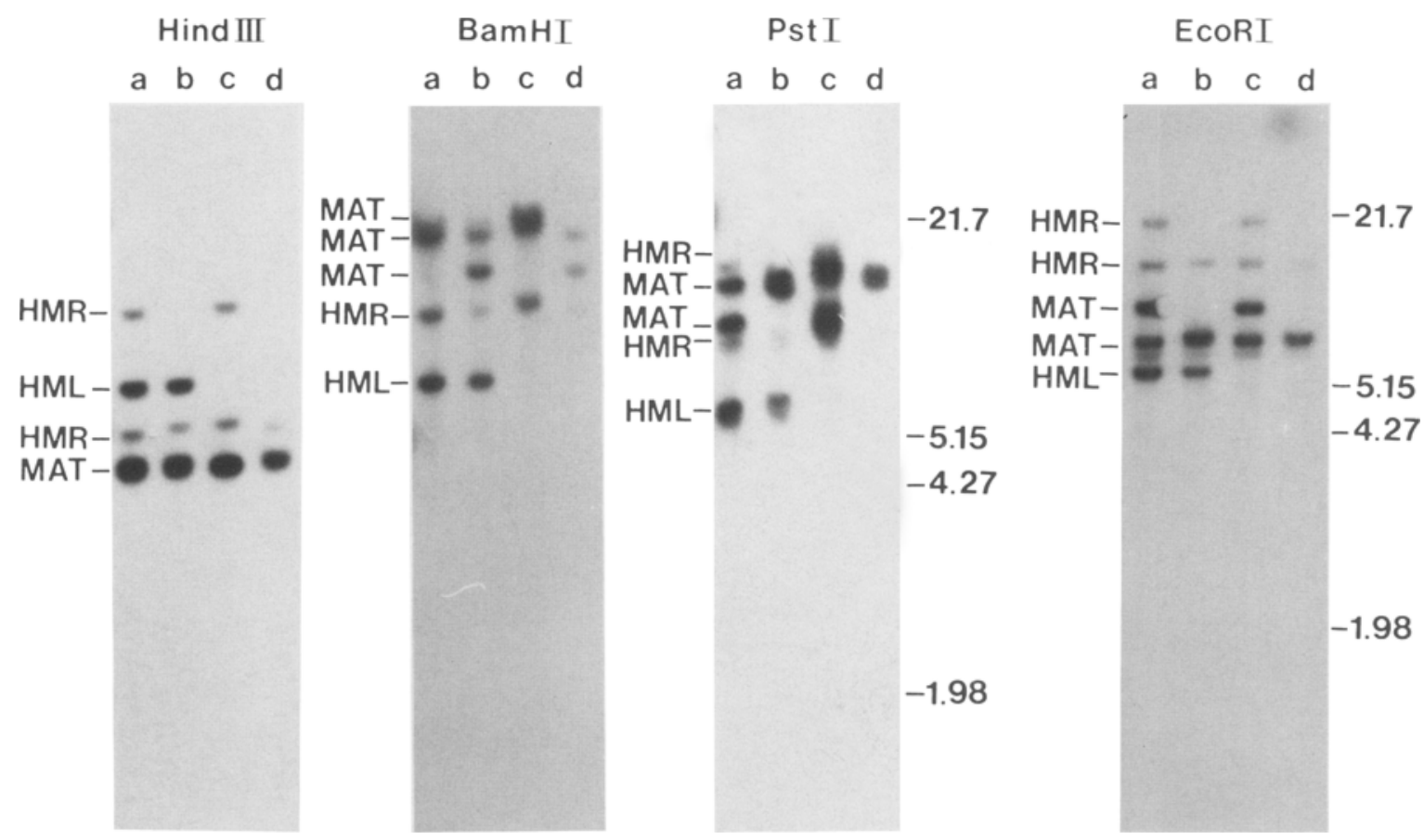

Figure 4d. Restriction endonuclease fragment analysis and identification of $M A T, H M L$ and $H M R$ in the 4 meiotic products $A_{353}-A_{356}$. Sizes are stated in $k b$. (a) $A_{353}$, (b) $A_{354}$, (c) $A_{355}$, (d) $A_{356}$.

In the PstI and EcoRI digests two bands and in the BamHI digest three bands indicated hybridization to the $M A T$ locus. Strain $\mathrm{A}_{211}$ (lanes d) showed in the BamHI digest two $M A T$ versions. They resulted in a larger and a normal sized fragment, respectively. The PstI digest of $A_{211}$ resulted in one enlarged fragment and the intensity indicated two copies. The EcoRI digest of $A_{211}$ resulted in one normal sized fragment and again the higher intensity indicated the presence of two copies. From this it is concluded that $\mathrm{A}_{211}$ contains two versions of the MATlocus, referred to as $M A T^{i}$ and $M A T^{\prime \prime}$. MAT $T^{i}$ is giving rise to the larger BamHI fragment, the enlarged PstI fragment and a normal sized EcoRI fragment. $M A T^{\prime \prime}$ is yielding normal sized BamHI and EcoRI fragments, combined with an enlarged PstI fragment. $\mathrm{A}_{212}$ (lanes e) showed in addition to $M A T^{\prime}$ another $M A T$ version named $M A T^{\prime \prime}$ which results in enlarged BamHI and EcoRI fragments and a normal sizes PstI fragment. $\mathrm{A}_{213}$ (lanes $\mathrm{f}$ ) showed in the Pstl and the EcoRI digests two $M A T$ versions by a normal sized fragment and an enlarged fragment. The BamHI digest resulted in one enlarged fragment and the intensity indicated two copies. From this it is concluded that $\mathrm{A}_{213}$ contains $M A T^{\prime \prime}$ and a $M A T$ version referred to as $M A T^{I l l}$ which is yielding enlarged BamHI and Pstl fragments and a normal sized EcoRI fragment. By analysing $\mathrm{A}_{214}$ in the same way, it can be seen that this strain contains $M A T^{\prime \prime}$ and $M A T^{\prime \prime}$.

The HindIII, BamHI, PstI and EcoRI digests of the strains $A_{277}-A_{280}, A_{325}-A_{328}$ and $A_{353}$ $-A_{356}$ are shown in Figures $4 b, 4 c$ and $4 d$. Similar to strains $A_{211}-A_{214}$, these three tetrads show independent segregation of four $M A T$ versions, three $H M R$ versions and one $H M L$ locus. One exception was observed: The BamHI, PstI and EcoRI digests of strain $A_{326}$ (Figure $4 c$, lanes b) all failed to reveal the expected fragment covering a $M A T$ locus but showed instead the presence of prevously unknown fragments, indicated by arrows. These fragments are supposed to cover a $M A T$ locus equivalent to $M A T^{\prime}$, since from the data from the three other strains in 

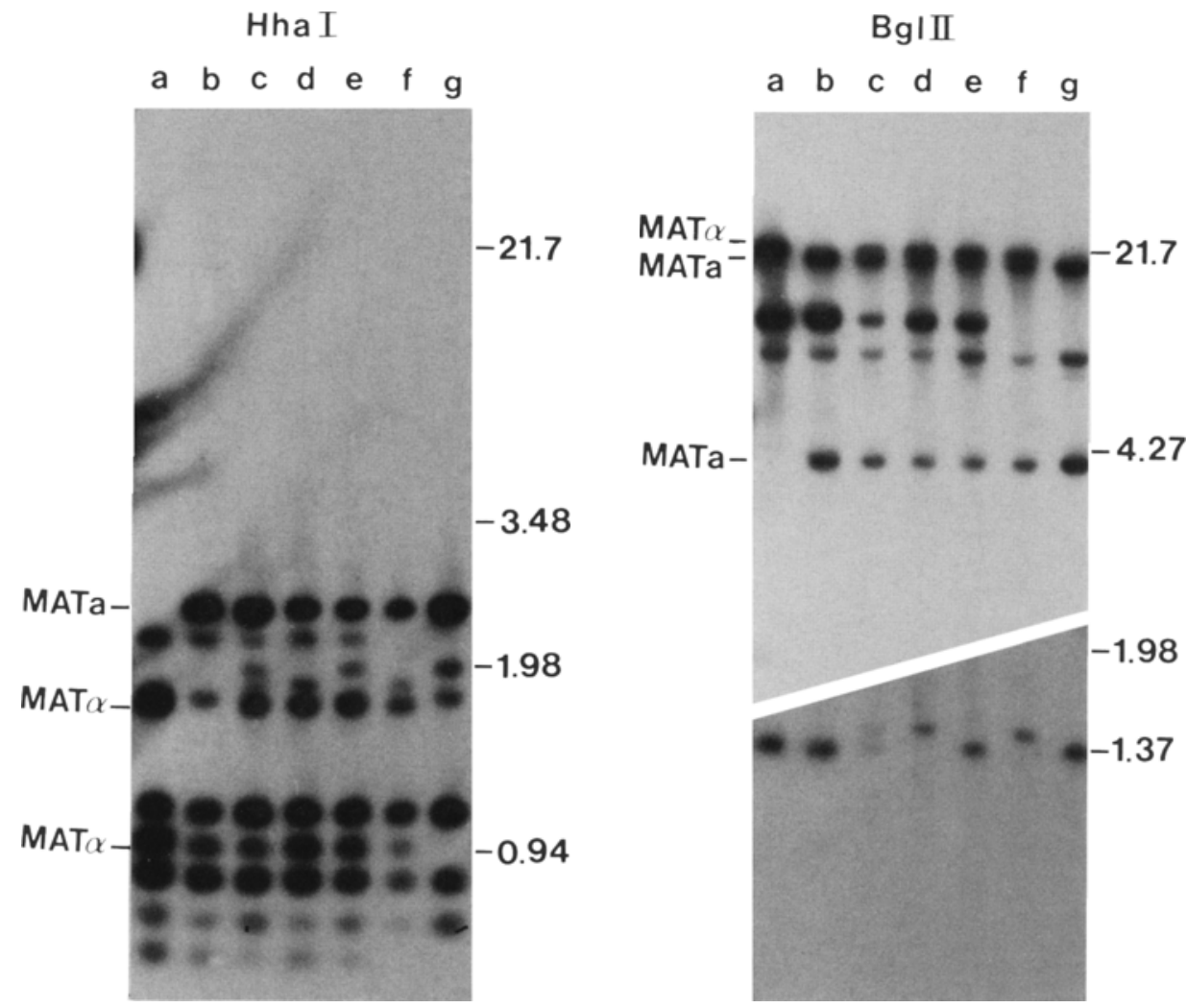

Figure 5a. Restriction endonuclease fragment analysis and identification of the MATa and MATa alleles in strain $A$ and its 4 meiotic products $A_{211}-A_{214}$. DNA from strains $S 288 C$ (a), A9275C (b), A (c) and $A_{211}-$ $A_{314}(d-g)$ were cleaved with $\mathrm{Hhal}$ and Bglll, subjected to electrophoresis in $0.7 \%$ agarose and transferred to a nitrocellulose filter. The DNA was hybridized to a ${ }^{32} \mathrm{P}$-labelled plasmid containing a $4.3 \mathrm{~kb}$ HindIIl fragment covering the entired $M A T \alpha$ gene, cloned from $\mathrm{S}$. cerevisiae. Sizes are stated in $\mathrm{kb}$.

this tetrad it is expected that $\mathrm{A}_{326}$ contains $M A T^{\prime}$ and $M A T^{V t}$.

The fragment patterns of HhaI- and BglII-digested DNA allow MATa and MATa to be distinguished from each other, as well as from $H M L$ and HMR. MATa digested with BglII results in two fragments, of $20 \mathrm{~kb}$ and $4.2 \mathrm{~kb}$, whereas $M A T a$ digested with BgllI yields one $24 \mathrm{~kb}$ fragment. Digested with HhaI MATa can be distinguished from $M A T \alpha$ by the presence of one $2.5 \mathrm{~kb}$ fragment instead of two fragments of $1.55 \mathrm{~kb}$ and $0.95 \mathrm{~kb}$. HMR a digested with Bglll results in fragments of the sizes $8.4 \mathrm{~kb}$ and $1.4 \mathrm{~kb}$, and $H M L \alpha$ digested with BgllI gives one $14 \mathrm{~kb}$ fragment. $H M R$ a digested with $\mathrm{HhaI}$ results in two fragments, of $1.6 \mathrm{~kb}$ and $0.6 \mathrm{~kb}$. $H M L a$ gives four fragments, of which two, of
$0.95 \mathrm{~kb}$ and $0.79 \mathrm{~kb}$, coincides with $M A T \alpha$ and two other, of $2.2 \mathrm{~kb}$ and $0.44 \mathrm{~kb}$, are unique. In Figure 5a Hhal- and BglII-digests of DNA from strains $A$ and $A_{211}-A_{214}$ are shown together with the MATa strain $\mathrm{S} 288 \mathrm{C}$ (lanes a) and the MATa strain A9275C (lanes b). S288C and A9275C exhibited the expected bands as mentioned above, shown by the restriction map in Figure $6(1,21,32)$ and listed in Table $X$.

By analysing the BglII and Hhal digests of the strains $A$ and $A_{211}-A_{214}$ it is seen, that the strains $\mathrm{A}$ and $\mathrm{A}_{211}-\mathrm{A}_{213}$ (lanes $\mathrm{c}, \mathrm{d}, \mathrm{e}, \mathrm{f}$ ) contain both the $M A T \mathrm{a}$ and the $M A T \alpha$ alleles. $\mathrm{A}_{214}$ (lanes $\mathrm{g}$ ) contains only the $M A T \mathbf{a}$ allele and the intensity of the $M A T \mathbf{a}$ bands indicates two copies of MATa in this strain. This observation is in agreement with the molecular analysis 

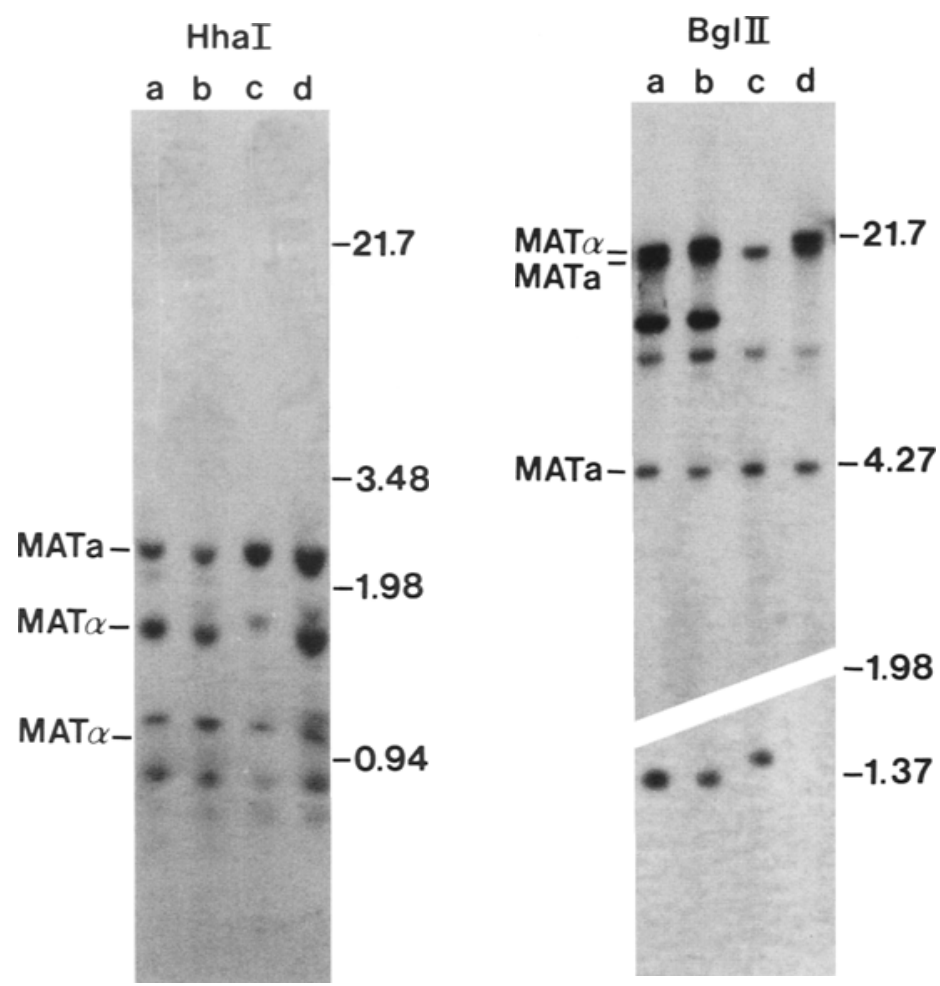

Figure $5 \mathrm{~b}$. Restriction endonuclease fragment analysis and identification of the $M A T \mathrm{a}$ and $M A T \alpha$ alleles in the 4 meiotic products $A_{277}-A_{280}$. Sizes are stated in kb. (a) $A_{277}$, (b) $A_{278}$, (c) $A_{279}$, (d) $A_{280}$.

described above on the distribution of MAT genes in the meiotic products and shows that $\mathrm{A}_{214}$, as well as the other meiotic products, contain two $M A T$ genes. The absence of $M A T \alpha$ in $\mathrm{A}_{214}$ agrees with the fact that this strain was found to show mating type $a$, in contrast to the other strains analysed which were found to be non-maters or weak maters (Table VI).

Differences between the three $H M R$ alleles, of which two in the HindIII, PstI and EcoRI digests were identified as similar, are revealed by the analysis of the BglII and Hhal digests. One $H M R$ allele, referred to as $H M R^{\prime}$, yields upon BglII digestion the normal sized fragments of $8.6 \mathrm{~kb}$ and $1.4 \mathrm{~kb}$. Another $H M R$ allele, referred to as $H M R^{I I}$, results in fragments of $8.6 \mathrm{~kb}$ and $1.5 \mathrm{~kb}$ and a third $H M R$ allele, $H M R^{\prime \prime \prime}$, gives fragments of $8.6 \mathrm{~kb}$ and $7.1 \mathrm{~kb}$. Also the Hhal digests of the three $H M R$ alleles are different (see Table $\mathrm{X}$ ). It is found that all three $H M R$ genes are alleles of the $H M R$ a gene, while $H M L$ is allelic to the $H M L \alpha$ gene. If $H M R^{\prime}$ had contained the $\alpha$ cassette the $1.6 \mathrm{~kb}$ Hhal fragment and its homologous in $H M R^{\prime \prime}$ and $H M R^{\prime \prime \prime}$ would be replaced by the two smaller fragments (cf. Figure 6). Likewise, the presence of the a cassette in $H M L$ would have yielded one $1.39 \mathrm{~kb}$ Hhal fragment instead of two of the fragments found (cf. Figure 6).

The HhaI and BgllI digests of the three other tetrads $\left(A_{277}-A_{280}, A_{325}-A_{328}\right.$ and $\left.A_{353}-A_{356}\right)$ are shown in Figure $5 \mathrm{~b}, 5 \mathrm{c}$ and $5 \mathrm{~d}$. In each of these tetrads three strains were found to contain both the $M A T \mathbf{a}$ and the $M A T \alpha$ alleles. The fourth strain of each tetrad contained two $M A T$ a alleles. Differences between three $H M R$ alleles were demonstrated, as well as absence of $H M L$ in two of four strains in each tetrad.

The sizes of restriction endonuclease fragments are listed in Table $\mathrm{X}$, the distributions 

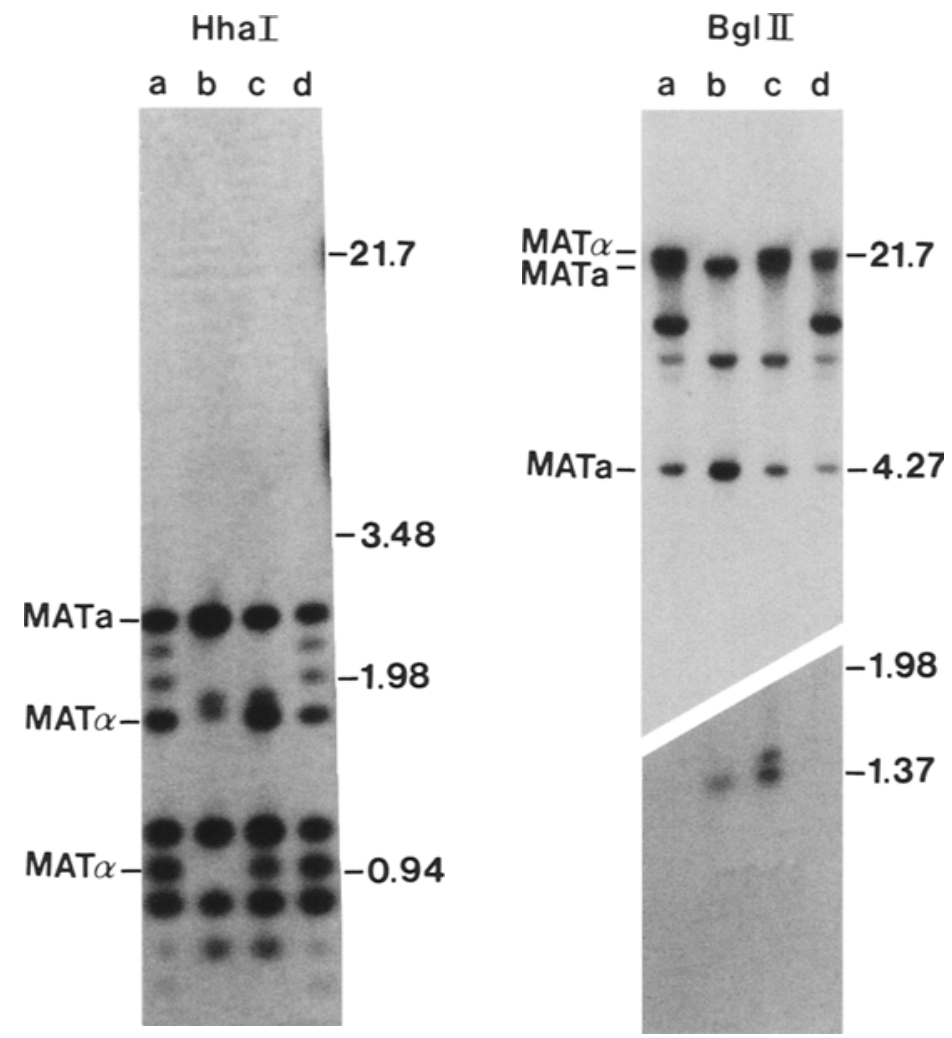

Figure 5c. Restriction endonuclease fragment analysis and identification of the $M A T \mathbf{a}$ and $M A T \alpha$ alleles in the 4 meiotic products $A_{325}-A_{328}$. Sizes are stated in $k b$. (a) $A_{325}$, (b) $A_{326}$, (c) $A_{327}$, (d) $A_{328}$.

of the MAT regions, MATa, MATa and $H M$ between the meiotic products are given in Table XI.

\subsubsection{Linkage between the LEU2, MAT and $H M$ alleles}

The molecular analysis indicates that strain A contains four chromosomes III, and the sporederived strains contain two chromosomes III.

The genes investigated provide the cell with all normal functions. Thus despite the differences found in some restriction patterns the genes can be assumed to be organized on chromosome III in the same order in strain A as in laboratory strains of S. cerevisiae. This assumption is supported by the finding that for all genes investigated some restriction fragments are identical in strain A and S288C.
On the basis of the segregation of genes in the four tetrads calculations have been made to determine which of the different $M A T$ and LEU2 regions are linked, see Table XII. Partial genetic maps of the four chromosomes III in strain $\mathrm{A}$, including $H M L$, are shown in Figure 7. No deductions can be made about the linkage between the $H M R$ regions and $M A T$ regions without additional markers as the distance is expected to be more than $50 \mathrm{cM}(31)$.

An unexpected presence of a total of $5 M A T$ a and $3 M A T \alpha$ alleles in each tetrad is found. This finding indicates the presence of the $H O$ (homothallism, chromosome IV) gene which can cause the homothallic shift of both $M A T$ a

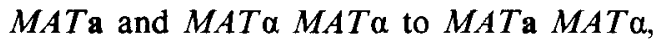
in the presence of $H M \alpha$ and $H M \mathrm{a}$, respectively. In the four spore-derived strains $\mathrm{A}_{214}, \mathrm{~A}_{279}, \mathrm{~A}_{326}$ and $\mathrm{A}_{355}$ the presence of two MATa alleles 
A.K. KEIDING: Characterization of distiller's yeast
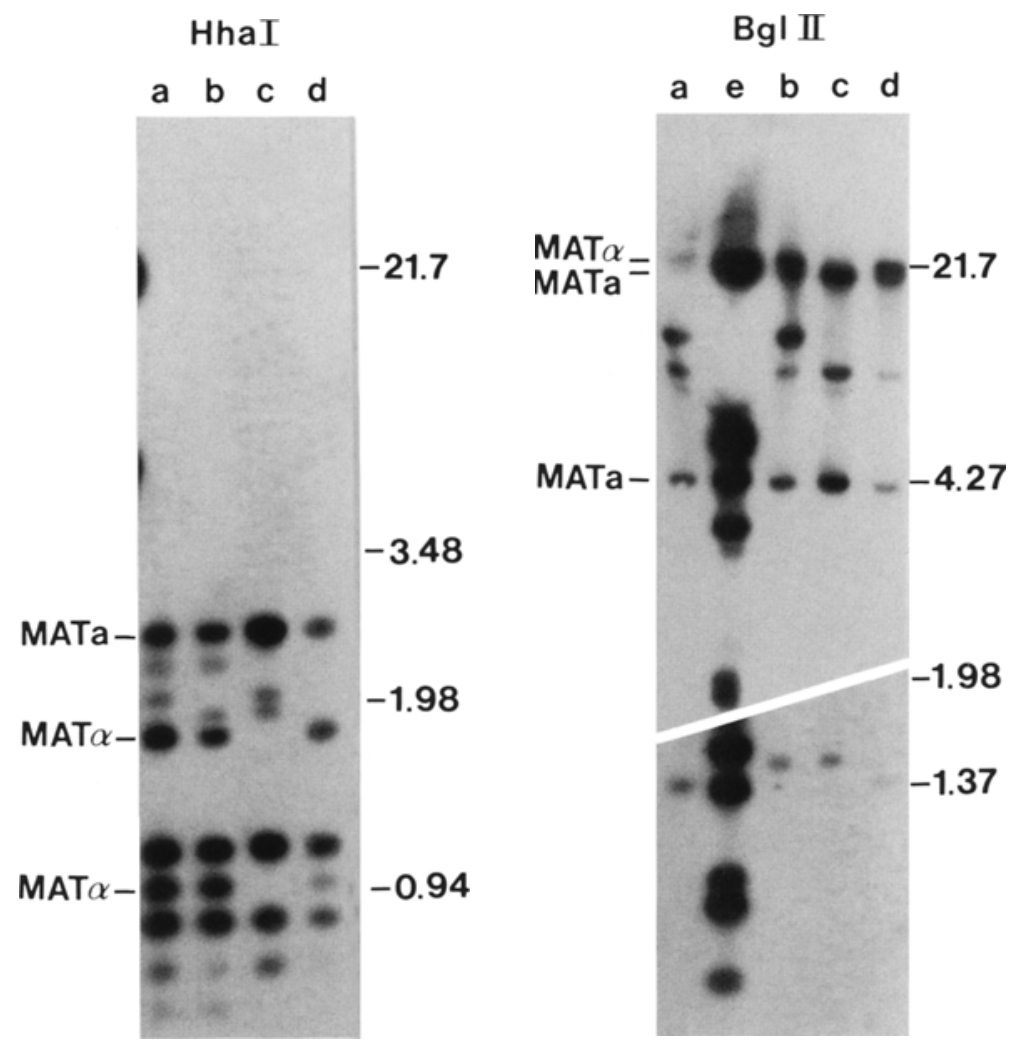

Figure $5 \mathrm{~d}$. Restriction endonuclease fragment analysis and identification of the $M A T \mathbf{a}$ and $M A T \alpha$ alleles in the 4 meiotic products $A_{333}-A_{356}$. Sizes are stated in kb. (a) $A_{333}$, (b) $A_{354}$, (c) $A_{355}$, (d) $A_{356}$, (e) $\lambda$ sizemarker.

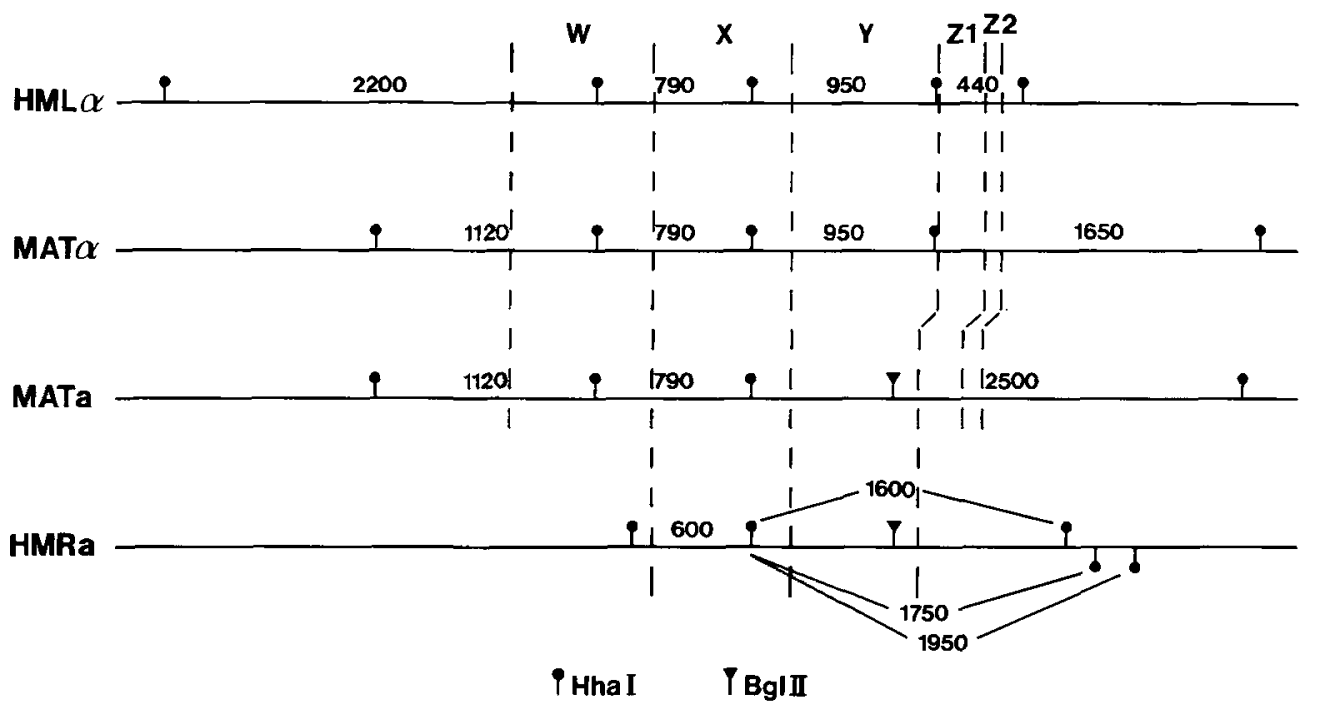

Figure 6. Partial restriction endonuclease map of the $M A T$ and $H M$ regions in S. cerevisiae strain $\mathrm{S} 288 \mathrm{C}$ (21, 32). Below the $H M R$ line, new sites found in strain $A$ are indicated. The two new $H$ haI sites found centromere-distal to $H M R$ in strain A are located in two different $H M R$ regions. Distances are expressed in bp. 
Table XII.

Determinations of theoretical distances in cM between pairs of $M A T$ and $L E U 2$

\begin{tabular}{|c|c|c|c|c|c|c|c|c|}
\hline & $M A T^{l}$ & & $M A T^{\prime \prime}$ & & $M A T^{\prime \prime \prime}$ & & $M A T^{\prime \prime}$ & \\
\hline$L E U 2^{I .4}$ & $\begin{array}{l}\text { PD: } \\
\text { NDP: } 0 \\
\text { TT: }\end{array}$ & & $\begin{array}{l}\text { PD: } \\
\text { NDP: } 0 \\
\text { TT: }\end{array}$ & & $\begin{array}{l}\text { PD: } \\
\text { NDP: } 1 \\
\text { TT: }\end{array}$ & $>50 \mathrm{cM}$ & $\begin{array}{l}\text { PD: } \\
\text { NDP: } 1 \\
\text { TT: }\end{array}$ & $>50 \mathrm{cM}$ \\
\hline$L E U 2^{2}$ & $\begin{array}{ll}\text { PD: } & 1 \\
\text { NDP: } & 2 \\
\text { TT: } & 1\end{array}$ & $>50 \mathrm{cM}$ & $\begin{array}{ll}\text { PD: } & 1 \\
\text { NDP: } & 1 \\
\text { TT: } & 2\end{array}$ & $>50 \mathrm{cM}$ & $\begin{array}{ll}\text { PD: } & 1 \\
\text { NDP: } & 1 \\
\text { TT: } & 2\end{array}$ & $>50 \mathrm{cM}$ & $\begin{array}{ll}\text { PD: } & 1 \\
\text { NDP: } & 0 \\
\text { TT: } & 3\end{array}$ & $38 \mathrm{cM}$ \\
\hline$L E U 2^{\prime}$ & $\begin{array}{ll}\text { PD: } & 1 \\
\text { NDP: } & 2 \\
\text { TT: } & 1\end{array}$ & $>50 \mathrm{cM}$ & $\begin{array}{ll}\text { PD: } & 0 \\
\text { NDP: } & 3 \\
\text { TT: } & 1\end{array}$ & $>50 \mathrm{cM}$ & $\begin{array}{ll}\text { PD: } & 2 \\
\text { NDP: } & 0 \\
\text { TT: } & 2\end{array}$ & $25 \mathrm{cM}$ & $\begin{array}{ll}\text { PD: } & 2 \\
\text { NDP: } & 0 \\
\text { TT: } & 2\end{array}$ & $25 \mathrm{cM}$ \\
\hline
\end{tabular}

${ }^{4}$ For $L E U 2^{\prime}$ it is not possible to determine PD and TT. The presence of 1 NDP results in a calculated distance larger than $50 \mathrm{cM}$.

coincides with the absence of the $H M L a$ gene. This combination prevents a homothallic shift to $M A T \mathbf{a} M A T \mathbf{a}$.

Following these analyses there are two possibilities for the genotype of strain A: 1) $M A T$ a $M A T \mathbf{a} M A T \mathbf{a} M A T \alpha$ or 2) MATa MATa MATa MATa.
In Table XIII, the genotypes of $A_{277}-A_{280}$ are explained on the basis of genotype 1). It is assumed that before homothallic shifts, $M A T^{\prime}$, $M A T^{\prime \prime}$ and $M A T^{\prime \prime}$ contain the MATa allele while $M A T^{\prime \prime \prime}$ contains $M A T \alpha$. This model is in agreement with the results observed for tetrads $A_{325}-A_{328}$ and $A_{353}-A_{356}$. Also the results

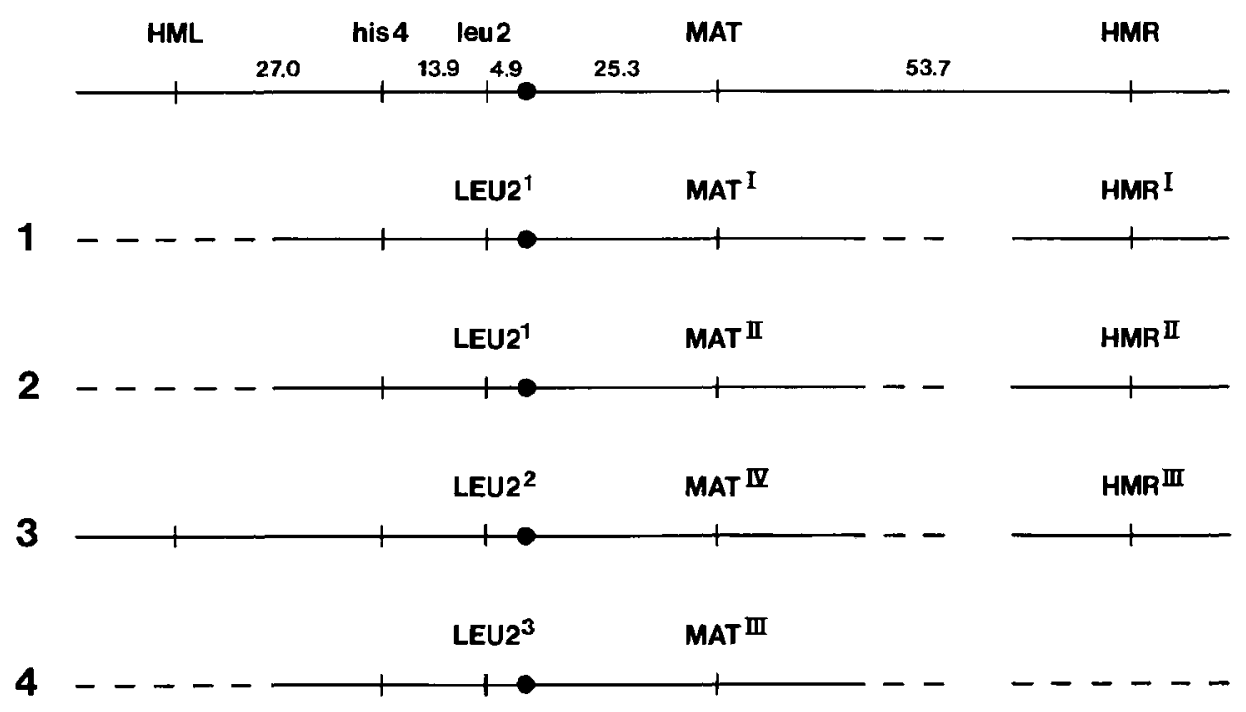

Figure 7. Model of the 4 chromosomes III in strain A with linkage of MAT, LEU2 and HML. A map of relevant markers on chromosome $I I I$ of standard strains of $S$. cerevisiae is shown at the top. The map distances, expressed in CM, are from MORTIMER and SCHILD (31). It is not possible to decide about the linkage between $M A T$ and $H M R$ from the available tetrads as indicated by the dashed lines. It is not known if some of the chromosomes are incomplete due to missing centromere-distal parts, or if these chromosomes are deficient only in $H M L$ and/or $H M R$. This is also indicated by dashed lines. 
Table XIII.

The genotypes of the spore-derived strains $A_{277}-A_{280}$ before and after homothallic shift if the genotype is MATa MATa MATa MATa

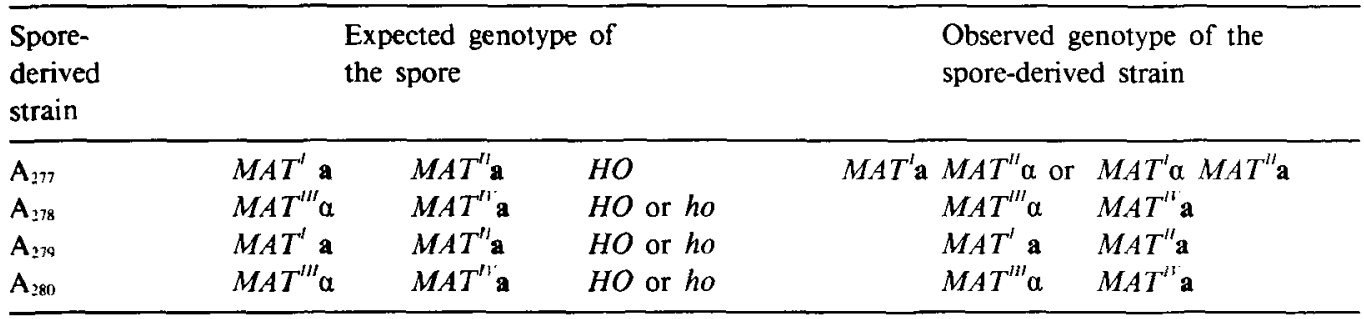

observed for tetrad $A_{211}-A_{214}$ can be explained in terms of this model. A crossing over between chromosome $\mathrm{III}_{1}$ and chromosome $\mathrm{III}_{3}$ (Figure 7) is required. The HindIII and EcoRI sites and the relative positions of the BamHI site of the $M A T^{\prime}$ and $M A T^{\prime \prime \prime}$ regions are shown in Figure 8. The crossing over had to occur in the region between the MAT locus and the unique BamHI site of $M A T^{\prime \prime I}$. Then the BamHI fragment of $M A T^{\prime}$ will look like the BamHI fragment of $M A T^{\prime \prime \prime}$ and vice versa. The region, in which the crossing over had to occur, is between 4 $\mathrm{kb}$ and $18 \mathrm{~kb}$ in length. It is reported to have a length of $15 \mathrm{~kb}-6 \mathrm{cM}(20)$. In a strain tetrasomic for a certain chromosome, crossing over in a region of this length is expected to occur in $24 \%$ of the tetrads in agreement with the present result where one cross over is found among four tetrads. An alternative distribution of $M A T$ alleles in the spore-derived strains $\mathrm{A}_{211}$ - $\mathrm{A}_{214}$ in accordance with this cross over is shown in Table X1. This does not result in changes in calculated linkage between $M A T$ and $L E U 2$. In all four tetrads $H O$ is demanded in one of the strains.

In Table XIV, the genotypes of $A_{277}-A_{280}$ are explained on the basis of the second possible genotype, $M A T$ a $M A T \mathbf{a} M A T \alpha M A T \alpha$. In the model shown in this table it is assumed that before homothallic shifts, $M A T^{\prime \prime}$ and $M A T^{\prime V}$ contain the $M A T \alpha$ allele, while $M A T^{\prime}$ and $M A T^{\prime \prime}$ contain $M A T \mathrm{a}$. The tetrad $\mathrm{A}_{353}-\mathrm{A}_{356}$ shows results which are in agreement with this assumption. It should be mentioned that in each of these two tetrads $\mathrm{HO}$ is required in three of the four strains. To explain the observations

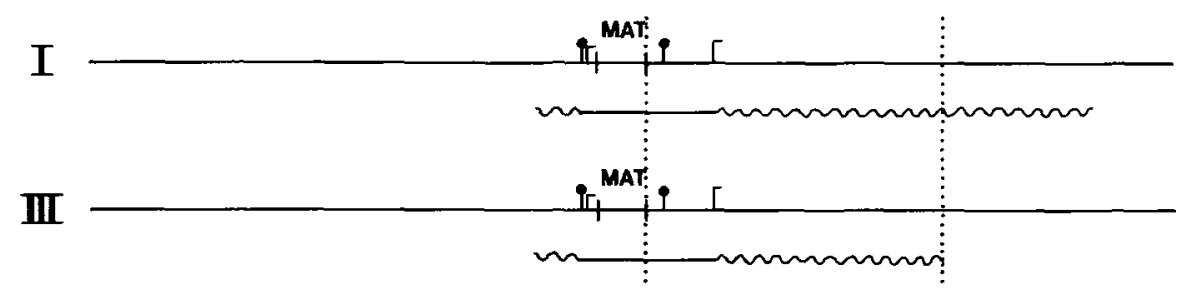

$4 \mathbf{k b}$

i Hind III Г EcoRI

Figure 8. Partial restriction map of the $M A T^{\prime}$ and the $M A T^{\prime \prime \prime}$ regions. Below each $M A T$ region is shown a possible location of the respective BamHI fragments. Both are known to cover the region between the HindIII site and the EcoRI site as indicated by the straight lines. The position of the BamHI sites is unknown as indicated by the wavy lines. It is assumed that on one side of the $M A T$ locus the BamHI sites of $M A T^{t}$ and $M A T^{I \prime \prime}$ are located identically. On the other side the sites are about $8 \mathrm{~kb}$ apart. A crossing over between the two dotted lines will result in a $M A T^{\prime}$ looking like $M A T^{\prime \prime \prime}$ and vice versa. The length between the two dotted lines can at a minimum be $4 \mathrm{~kb}(\sim 1.6 \mathrm{cM})$ and at a maximum $18 \mathrm{~kb}(\sim 7.5 \mathrm{cM})$. The most likely distance between the $M A T$ locus and the right BamHI site of $M A T^{\prime \prime \prime}$ is as shown on the figure $15 \mathrm{~kb}(\sim 6 \mathrm{cM})(20)$. 
Table XIV.

The genotypes of the spore-derived strains $A_{277}-A_{280}$ before and after homothallic shift if the genotype is MATa MATa MATa MATa

\begin{tabular}{|c|c|c|c|c|c|c|}
\hline \multirow{2}{*}{$\begin{array}{l}\text { Spore- } \\
\text { derived } \\
\text { strain }\end{array}$} & \multicolumn{3}{|c|}{$\begin{array}{l}\text { Expected genotype of } \\
\text { the spore }\end{array}$} & \multicolumn{3}{|c|}{$\begin{array}{l}\text { Observed genotype of the } \\
\text { spore-derived strain }\end{array}$} \\
\hline & $M A T^{\prime} \mathbf{a}$ & $M A T^{\prime \prime} \mathrm{a}$ & HO & $M A T^{\prime} \mathbf{a}$ & $M A T^{\prime l} \alpha$ or & $M A T^{l} \alpha M A T^{\prime \prime}$ \\
\hline $\mathrm{A}_{278}$ & $M A T^{\prime \prime \prime} \alpha$ & $M A T^{\prime \prime} \alpha$ & HO & $M A T^{\prime \prime \prime} \alpha$ & $M A T^{\prime \prime}$ a or & $M A T^{\prime \prime \prime} \mathbf{a} M A T^{\prime \prime} \alpha$ \\
\hline $\mathbf{A}_{279}$ & $M A T^{\prime} \mathbf{a}$ & $M A T^{\prime \prime}$ & HO or ho & & $M A T^{\prime} \mathbf{a}$ & $M A T^{\prime \prime} \mathbf{a}$ \\
\hline $\mathrm{A}_{280}$ & $M A T^{\prime \prime \prime} \alpha$ & $M A T^{\prime \prime} \alpha$ & HO & $M A T^{7 I} \alpha$ & $M A T^{n} \mathbf{a}$ & or $M A T^{n l}$ a $M A T^{n \prime} \alpha$ \\
\hline
\end{tabular}

made in the tetrad $A_{211}-A_{214}$ the opposite assumption should be made: In strain A, $M A T^{\prime \prime \prime}$ and $M A T^{\prime \prime}$ have to contain $M A T \mathbf{a}$, whereas $M A T^{\prime}$ and $M A T^{I l}$ have to contain $M A T \alpha$. The tetrad $\mathrm{A}_{325}-\mathrm{A}_{328}$ requires a third combination of $M A T$ regions. On the whole this alternative is unlikely.

\section{DISCUSSION}

Several genetic analyses were performed with strain $A$ and its meiotic segregants. These included rare mating of strain $A$, isolation of auxotrophic mutants, tests of mating ability of meiotic segregants and tetrad analysis of crosses between meiotic segregants and standard strains of S. cerevisiae. They all support the assumption that strain $A$ is polyploid and that its meiotic segregants show mitotic instability most probably due to chromosome loss and mating type shifts. This is demonstrated by the appearance of maters from strains characterized as non-maters and vice versa.

At least 20 auxotrophic mutants of independent origin have been isolated from meiotic segregants of strain A. Of these 16 were found to be allelic to known genes on chromosomes I, II, IV, VII, XI and XII in S. cerevisiae. Mutations were obtained in at least 10 loci as some of the 16 mutations were allelic. Since strain A was only found heterozygous for ade3, all other mutants have been induced by the mutagen treatment. In spite of the polyploid or aneuploid nature of strain $A$ and its meiotic segregants it is possible to isolate recessive mutants. There are three possible explanations for the appearance of recessive mutants in polyploid strains. 1) The mutation is induced in a strain monosomic for the chromosome in question. 2) The mutation is induced in a chromosome for which the strain is disomic but the homologous wildtype chromosome is subsequently lost. 3) The mutation is induced in a chromosome for which the strain is disomic but mitotic recombination results in cells homozygous for the mutant allele.

Sporulation and analysis of dissected spores from a cross between $A_{91}$ and a tester strain has revealed in this meiotic segregant monosomy of chromosome IV and disomy of chromosomes I, V, VI, VII and XI, whereas $A_{209}$ was found to be disomic for all these six chromosomes. Mutagenesis of $A_{91}$ and $A_{209}$ produced different results since $A_{91}$ yielded mutations in several loci while only ade3 mutants, probably as segregants of an inherent mutant were found in $A_{209}$. As $A_{91}$ is monosomic for chromosome IV it is perhaps more amenable to chromosome loss than $A_{209}$ which as far as tested is euploid. This might explain the different behaviour of the two strains.

The presence of an ade 3 mutation in strain $\mathrm{A}$ is demonstrated: Ade 3 mutants appeared from strain A upon sporulation as well as after UVand EMS-treatment of spore-derived lines. Furthermore, progeny analysis from the cross of the meiotic segregant $A_{91} \times$ marker strain $N 248$ $1 \mathrm{~A}$ also yielded ade 3 mutants. In a normal tetraploid strain triplex for a certain wildtype gene, predominantly 4:0 segregations of wildtype to mutant are expected. A few 3:1 segregations, i.e. one mutant spore/ascus, and no 2:2 segregations are found $(13,39)$. The presence of three ade 3 mutants among the 284 tested 
offsprings of strain A makes it likely that strain $A$ is tetrasomic for the chromosome carrying the Ade 3 gene (chromosome VII), and that one of the genes is mutated. As a consequence, $A_{91}$ and $\mathrm{A}_{209}$ are both believed to be at least disomic for chromosome VII and heterozygous for Ade 3 . The ade 3 mutants expressed after UV- and EMS-treatment are revealed as a result of mitotic recombination or chromosome loss. Another less likely explanation can be proposed, namely that the Ade3 gene contains a hot spot region for mutations, and that the ade 3 mutants obtained are induced independently.

Upon mating of strain A with the tester strains according to the rare mating technique it is revealed that predominantly a maters are produced (Table III). The result can indicate that strain A contains one $M A T \alpha$ allele and at least two $M A T$ a alleles and thus at least three chromosomes III are present. This assumption is supported by the results obtained in the molecular characterization. The notable appearance of a maters in experiment 5 of Table III could be due to loss of the MAT $\alpha$ allele in the early phase of the growth of the single colony chosen for this experiment. Significant differences between the frequencies of a maters among rare mating products on solid media and in liquid media were observed. If the cells that express mating type have a poor mating ability they might divide preferentially several times before mating, which in liquid medium will result in several mating products originating from one mater, while only one mating product will be scored on solid medium. This would result in differences of the type observed.

The results of individual spore analysis of strain A support the deduction that at least two $M A T \mathrm{a}$ and a single $M A T \alpha$ are present in this strain as a majority of the maters found among meiotic segregants are MATa maters. Many meiotic segregants were found to sporulate, due to the presence of both $M A T \mathrm{a}$ and $M A T \alpha$. The absence of viable spores in many asci is probably caused by aneuploidy as a result of reduced recombination. (Some sporulators were found to mate, possibly due to mitotic instability.)

Restriction endonuclease fragment analyses were made on meiotic segregants of strain A by hybridization of ${ }^{32} \mathrm{P}$-labelled probes (HIS4,
$L E U 2, M A T \alpha$ ) to restricted DNA fixed to a nitrocellulose filter. On the basis of these results it is concluded that strain $A$ is tetrasomic for chromosome III. An alternative explanation can be suggested: Three large regions of chromosome III, containing respectively the LEU2 gene, the $M A T$ gene and the $H M R$ locus, i.e. the entire region from $L E U 2$ to $H M R$, are duplicated twice somewhere in the genome. This possibility is considered highly unlikely as it demands several large duplications which include both sides of the centromere.

HIS4, LEU2, MAT, HML and HMR have been analysed and for each $M A T$ it has been determined if it contains the $M A T$ a or $M A T \alpha$ cassette. Previously it has been found that these loci from different Saccharomyces species have different restriction endonuclease fragment patterns (33, 35). Many of the tested restriction endonuclease recognition sites in this chromosomal region of strain $\mathrm{A}$ are the same as those observed in the standard line S288C (1, 6, 9, $21,23,32,45,46)$. However, the four chromosomes III in strain A are distinguishable in the $L E U 2, M A T$ and $H M R$ regions by the presence of not previously reported restriction sites adjacent to these loci. It is concluded that the chromosomes III present in strain A show a high degree of structural homology to the wild type chromosome III of the standard genetic strain S288C.

The restriction fragment patterns found in the LEU2 region of S. cerevisiae strain $\mathrm{M} 127$ by DOBSON et al. (9) have similarities to those found in strain A. Strain M127 exhibits three bands when digested with EcoRI and hybridized to a ${ }^{32}$ P-labelled plasmid containing the $L E U 2$ gene cloned from M127. These three bands were shown to segregate in spore-derived strains. Furthermore, M127 shows about $45 \%$ spore viability (none of the asci micro dissected contained four viable spores) and a majority of the spore-derived strains were non-maters. Also strain A exhibits three bands hybridizing to a probe containing part of the $L E U 2$ gene when its DNA is digested with certain restriction enzymes including EcoRI. These three bands segregate in the tetrads analyzed. By dissection of 4 -spored asci the spore viability was $42 \%$, but in four asci all four spores were viable and 
a majority of the spores were non-maters (7). According to a personal communication from C. Christiansen, M127 was derived from strain A in 1968 and subsequently sent to J.D. BEGGS. As the two strains still behave very similarly, it can be concluded that the production strain is stable despite the remarkable mitotic instability of the meiotic segregants observed in this study.

BEGGS (2) has isolated LEU2 from one of the chromosomes III of M127 and DoBSON et al. (9) established that no Ty element but only a $\delta$ sequence was located next to the $t R N A_{3}^{\text {lew }}$ and LEU2 on that chromosome III. A XhoI site is present in the $\delta$ sequence (see Figure 3 ). Furthermore, on at least one of the chromosomes III from M127 a XhoI site is present between the $t R N A$ gene and $\delta$, separated from the other XhoI site by $180 \mathrm{bp}$ (9). On the gel, the recognizable sizes of the Xhol fragments from strain $A$ and its meiotic segregants are indistinguisable from that of the Xhol fragment of $\mathrm{S288C}$ even if a difference of $180 \mathrm{bp}$ should exist. As restriction fragments having the same size are taken to be homologous, it is likely that all four chromosomes III of strain A contain at least one of the two XhoI sites described above. Based on the restriction endonuclease fragment patterns obtained the $T y 1-17$ transposable element of $\mathrm{S} 288 \mathrm{C}$, located in the immediate vicinity of $L E U 2$ is absent in strain $\mathrm{A}$. The presence of another $T y$ element connected to the $\delta$ which is present at least on one of the four chromosomes III can not be excluded. However, I could not locate any of the restriction sites found distal to $\delta$ in published sequences of other $T y$ elements $(T y 1, T y 1-B 1, T y 1-B 10$, Ty1-D15, Tyl-S11, Tyl-S12, Ty1-S13, Ty1S15, Ty1-161, Ty61, Ty128, Ty173, Ty900, Ty901, Ty902, Ty912) (4, 11, 15, 28, 38, 42).

Based on the restriction endonuclease fragment analysis of $M A T \mathbf{a} / M A T \alpha$ in the sporederived strains (section 3.6.5) it is deduced that strain $\mathrm{A}$ is of the constitution MATa MATa $M A T$ a $M A T \alpha$. The presence of the dominant gene $H O$ is required to explain the occurrence of maters and non-maters.

The tetrad analysis uncovered that only one copy of the $H M L$ gene and three copies of the $H M R$ gene are present on the four chromosomes
III of strain A. The three $H M R$ genes are distinguished by their restriction fragment patterns. Two explanations for the presence of only four instead of eight silent mating type genes on four chromosomes can be suggested. 1) The regions which contain $M H L$ or $H M R$ are deleted from certain versions of chromosome III. 2) The regions are present but the nucleotide sequence of the $H M L$ and $H M R$ alleles is so different that hybridization to the probe is excluded. $G$. FINK (pers. comm.) has found an essential gene located about $2 \mathrm{cM}$ centromere-distal to HIS4. Thus, regardless of sizes, deletions covering $H M L$ on the left arms of three of the four chromosomes III can probably not cover this gene. The deletion of $H M R$ deduced on one of the right arms is probably centromer-distal to $c d c 39$.

In conclusion, strain A is tetrasomic for chromosome III. Two meiotic segregants are disomic for several chromosomes and thus the possibility exists that strain $\mathrm{A}$ is an allotetraploid. Inside the genes investigated no differences in the restriction sites have been detected between genetic standard strains and strain $\mathrm{A}$.

I wish to point out some consequences from the results of the genetic and molecular analysis for attemps to improve the performance of strain $A$ as a distiller's yeast. The knowledge of the molecular constitution of chromosome III as well as the knowledge of the presence of $\mathrm{HO}$ allows one to construct heterothallic and homothallic derivatives which can be used to reorganize the gene content in strain $A$ using its inherent genetic variation. Such derivatives with known constitutions of $M A T, H M L, H M R$ and $H O$ are required if commercially useful hybrids are to be produced in a planned way. In this paper it is shown that it is possible to isolate mutants from meiotic segregants of an industrial S. cerevisiae even if it is tetrasomic for most of its chromosomes. The availability of recessive counter-selectable mutants such as auxotrophs is a prerequisite for strain improvement by cross breeding and genetic transformation with isolated DNA. Strain A is to a large extent genetically similar to characterized standard strains and it can thus be anticipated that any $S$. cerevisiae gene harboured on a transformation vector can be expressed in it. The auxotrophic 
derivatives, which after transformation can be hybridized to yield an industrial strain will be of help for such endeavours.

\section{ACKNOWLEDGEMENTS}

I wish to express my gratitude to TORSTEN NILSSON-TILlgREN and Diter vON WETTSTEIN for many stimulating and helpful discussions and for critical reading of the manuscript. Thanks are also due to SteEn HOLMBERG, Morten Kielland-Brandt, Bjørn ChriStensen, Claes Gjermansen and Søren W. RASMUSSEN for advice and fruitful discussions.

\section{REFERENCES}

1. Astell, C.R., L. Ahlstrom-Jonasson \& M. SMITH: The sequence of the DNAs coding for the mating-type loci of Saccharomyces cerevisiae. Cell 27, 15.23 (1981)

2. BEGGS, J.D.: Transformation of yeast by a replicating hybrid plasmid. Nature 275, 104-109 (1978)

3. Birn boim,H.C.\& J. Doly: A rapid alkaline extraction procedure for screening recombinant plasmid DNA. Nucl. Acids Res. 7, 1513-1523 (1979)

4. CAMERON, J.R., E.Y. LoH \& R.W. DAvis: Evidence for transposition of dispersed repetitive DNA families in yeast. Cell, 16, 739-751 (1979)

5. Cameron. J.R., P. Phillippsen \& R. W. Davis: Analysis of chromosomal integration and deletions of yeast plasmids. Nucl. Acids Res. 4, 14291448 (1977)

6. Chinault, A.C. \& J. CaRbon: Overlap hybridization screening: Isolation and characterization of overlapping DNA fragments surrounding the LEU2 gene on yeast chromosome III. Gene 5, 111-126 (1979)

7. Christensen, B.E.: Cross-breeding of distillers yeast. Carlsberg Res. Commun. in preparation (1985)

8. DenHARDT, D.T.: A membrane-filter technique for the detection of complementary DNA. Biochem. Biophys. Res. Commun. 23, 641-646(1966)

9. DoBson, M.J., S.M. KingSMAN \& A.J. KINGSMAN: Sequence variation in the $L E U 2$ region of the Saccharomyces cerevisiae genome. Gene 16, 133139 (1981)

10. EMEIS. C.C.: Polyploide Kulturhefen. Eur. Brew. Conv. Congr., Wien, 205-215 (196l)

11. Farabaugh, P.J. \& G.R. Fink: Insertion of the eukaryotic transposable element $T y l$ creates a 5-base pair duplication. Nature, 286, 352-355 (1980)
12. FinchaM, J.R.S.: Genetics. Wright (1983)

13. FINCHAM, J.R.S., P.R. DAY \& A. RADFORD: Fungal genetics. Blackwell Scientific Publications, Oxford, 4. edition (1979)

14. FoweLl, R.R.: Sporulation and hybridization of yeasts. In: The yeasts. A.H. Rose \& J. Harrison, eds., Academic Press, New York, vol. I, 303-383 (1969)

15. GAfNer, J. \& P. PhilipPSEN: The yeast transposon Tyl generates duplications of target DNA on insertion. Nature, 286, 414-418 (1980)

16. GuNGE, N.: Breeding of bakers yeast - determination of the ploidy and an attempt to improve practical properties. Japan. J. Genetics 41, 203 214 (1966)

17. GunGE, N.\& Y. NAKatomi: Genetic mechanisms of rare matings of the yeast Saccharomyces cerevisiae heterozygous for mating type. Genetics 70 , 41-58 (1972)

18. Hawthorne, D.C. \& R.K. Mortimer: Chromosome mapping in Saccharomyces: centromerelinked genes. Genetics 45, $1085-1100$ (1960)

19. HAYNES, R.H. \& B.A. KUNZ: DNA repair and mutagenesis in yeast. In: The Molecular Biology of the Yeast Saccharomyces. Life Cycle and Inheritance. J.N. Strathern, E.W. Jones \& J.R. Broach, eds., Cold Spring Harbor Lab., $371-414$ (1981)

20. HICKS, J., J.N. STRATHERN \& A.J.S. KLAR: Transposable mating type genes in Saccharomyces cerevisiae. Nature 282, $478-484$ (1979)

21. Holmberg, S.: Genetic differences between Saccharomyces Carlsbergensis and $\mathbf{S}$. cerevisiae. II. Restriction endonuclease analysis of genes in chromosome III. Carlsberg Res. Commun. 47, 233-244 (1982)

22. Holmberg, S., J.G.L. Petersen, T. NilssonTillgren \& M. Kielland-Brandt: Molecular characterization of a Saccharomyces plasmid containing the HIS4 gene. Carlsberg Res. Commun. 44, 269-282 (1979)

23. HolmberG, S., M. Kielland-BrandT, $T$. Nilsson-Tillgren \& J.G.L. Petersen: Molecular characterization of three HIS4 deletion mutants in Saccharomyces cerevisiae. Carlsberg Res. Commun. 44, 283-288 (1979)

24, JAMES, A.P. \& E.R. INHABER: Evidence of preferential pairing of chromosomes at meiosis in aneuploid yeast. Genetics 79, 561-571 (1975)

25. JefFreys, A.J. \& R.A. Flavell: A physical map of the DNA regions flanking the rabbit $\beta$-globin gene. Cell 12, $429-439$ (1977)

26. JONES, E.W.\& K.B. LAM: Mutations affecting levels of tetrahydrofolate interconversion enzymes in Saccharomyces cerevisiae. II. Map position on chromosome VIl of ade3-41 and $A D E 15$. Molec. 
Gen. Genet. 123, 209-218 (1973)

27. Kielland-Brandt,M.C., T. NilsSon-Tillgren, S. HOLMBERG, J.G.L. PETERSEN \& B.A. SVENNINGSEN: Transformation of yeast without the use of foreign DNA. Carlsberg Res. Commun. 44, 77-87 (1979)

28. Kingsman, A.J., R.L. Gimlich, L. Clarke, A.C. Chinault \& J. Carbon: Sequence variation in dispersed repetitive sequences in Saccharomyces cerevisiae. J. Mol. Biol. 145, 619-632 (1981)

29. KLAPHOLZ, S. \& R.E. EsPOSITO: A new mapping method employing a meiotic Rec mutant of yeast. Genetics 100, 387-412 (1982)

30. Maniatis, T., E.F. FritsCh \& J. SAmbrook: Molecular cloning. A laboratory manual. Cold Spring Harbor Lab. 1982

31. MORTIMER, R.K \& D. SCHILD: Genetic map of Saccharomyces cerevisiae. Microbiol. Rev. 44, 519-561 (1982)

32. NASMYTH, K.A. \& K. TATCHELL: The structure of transposable yeast mating type loci. Cell 19, 753764 (1980)

33. Nilsson-Tillgren, T., C. Gjermansen, M.C. Kielland-Brandt, J.G.L. Petersen \& S. HolmBERG: Genetic differences between Saccharomyces carlsbergensis and $\mathbf{S}$. cerevisiae. Analysis of chromosome III by single chromosome transfer. Carlsberg Res. Commun. 46, 65-76 (1981)

34. PARRY, E.M. \& B.S. Cox: The general properties of a strain of yeast with less DNA than normal. J. Gen. Microbiol. 70, 129-149 (1972)

35. Pedersen, M.B.: DNA sequence polymorphisms in the genus Saccharomyces. I. Comparison of the HIS 4 and ribosomal RNA genes in lager strains, ale strains and various species. Carlsberg Res. Commun. 48, 485-503 (1983)

36. Rigby, P.W.J., M. Doeckmann, C. Rhodes \& P. BERG: Labeling deoxyribonucleic acids to high specific activity in vitro by nick translation with DNA polymerace I. J. Mol. Biol. 113, 237-251 (1977)

37. RILEY, M.I. \& T.R. MANNEY: Tetraploid strains of Saccharomyces cerevisiae that are trisomic for chromosome III. Genetics 89, 667-684 (1978)

38. ROEDER, G.S., M. SMITH \& E.J. LAMBIE: Intrachro- mosomal movement of genetically marked Saccharomyces cerevisiae transposons by gene conversion. Mol. Cell. Biol. 4, 703-711 (1984)

39. Roman, H., M.M. PhilliPS \& S.M. Sands: Studies of polyploid Saccharomyces. I. Tetraploid segregation. Genetics 40, 546-561 (1955)

40. SChAEFFER, A.B. \& M. Fulton: A simplified method of staining endospores. Science 77, 194 (1933)

41. Shaffer, B., I. Brearley, R. LittLewoOd \& G.R. FINK: A stable aneuploid of Saccharomyces cerevisiae. Genetics 67, 483-495 (1971)

42. Simchen, G., F. Winston, C.A. Styles \& G.R. FINK: Ty-mediated gene expression of the LYS2 and HIS4 genes of Saccharomyces cerevisiae is controlled by the same SPT genes. Proc. Natl. Acad. Sci. USA, 81, 2431-2434 (1984)

43. Slonimski, P.P., G. Perrodin \& J.H. Croft: Ethidium bromide induced mutation of yeast mitochondria: Complete transformation of cells into respiratory deficient non-chromosomal "petites". Biochem. Biophys. Res. Commun. 30, 232-239 (1968)

44. SOUTHERn, E.M.: Detection of specific sequences among DNA fragments separated by gel electrophoresis. J. Mol. Biol. 98, 503-517 (1975)

45. Storms, R.K., J.B. McNeIl, P.S. KhandekaR, G. AN, J. PARKER \& D.J. FRIESEN: Chimeric plamids for cloning of deoxyribonucleic acid sequences in Saccharomyces cerevisiae. J. Bacteriol. 140, 73-82 (1979)

46. Strathern, J.N., E. Spatola, C. McGill \& J.B. Hicks: Structure and organization of transposable mating type cassettes in Saccharomyces yeasts. Proc. Natl. Acad. Sci. USA 77, 2839-2843 (1980)

47. Walton, E.F., B.L.A. CARTER \& J.R. Pringle: An enrichment method for temperature-sensitive and auxotrophic mutants of yeast. Mol. Gen. Genet. $171,111-114$ (1979)

48. ZIMMERMANN, F.K.: Detection of genetically active chemicals using various yeast systems. In: Chemical mutagens. Priciples and Methods for their Detection. A. Hollaender ed., Plemun Press. New York - London, vol. III, 209-239 (1973)

Accepted by: H. KLENOw, E. LuND \& S.O. ANDERSEN 